Supplementary Information for

\title{
Synthesis of Sterically Protected Xanthene Dyes with Bulky Groups at C-3' and C-7'
}

Zuhai Leił, Xinran Lił, Yi Lił, Xiao Luoł, Miaomiao Zhoułand Youjun Yang†ł*

$\dagger$ State Key Laboratory of Bioreactor Engineering, $₫$ Shanghai Key Laboratory of Chemical Biology, School of Pharmacy, East China University of Science and Technology, Meilong Road 130, Shanghai 200237, China

E-mail: youjunyang@ecust.edu.cn

Table of Content

\begin{tabular}{|c|c|}
\hline Page\# & Content \\
\hline S3 & General methods \\
\hline S4 & $\begin{array}{l}\text { Figure S1: Absorption, excitation and emission spectra of } \mathbf{7 e - I} \text {, and } \mathbf{1 1 .} \\
\text { Figure S2, aggregation of } \mathbf{7 i} \text {. } \\
\text { Figure S3: Chemostability test of } \mathbf{7 h} \text { and } \mathbf{7 i} \text {. }\end{array}$ \\
\hline S5 & Figure S4. The ${ }^{1} \mathrm{H}-\mathrm{NMR}$ of compound $2 \mathrm{a}$ in $\mathrm{CDCl}_{3}$. \\
\hline S6 & Figure S5. The ${ }^{1} \mathrm{H}-\mathrm{NMR}$ of compound $\mathbf{2} \mathbf{b}$ in $\mathrm{CDCl}_{3}$. \\
\hline S7 & Figure S6: The ${ }^{1} \mathrm{H}-\mathrm{NMR}$ of compound $3 \mathrm{a}$ in $\mathrm{CDCl}_{3}$. \\
\hline S8 & Figure S7: The ${ }^{13} \mathrm{C}$-NMR of compound $3 \mathrm{a}$ in $\mathrm{CDCl}_{3}$ \\
\hline S9 & Figure S8: The EI-MS of compound 3a. \\
\hline S10 & Figure S9: The ${ }^{1} \mathrm{H}-\mathrm{NMR}$ of compound $\mathbf{3 b}$ in $\mathrm{CDCl}_{3}$. \\
\hline S11 & Figure S10: The ${ }^{13} \mathrm{C}$-NMR of compound $\mathbf{3 b}$ in $\mathrm{CDCl}_{3}$. \\
\hline S12 & Figure S11: The HR-MS of compound $\mathbf{3 b}$. \\
\hline $\mathrm{S} 13$ & Figure S12: The ${ }^{1} \mathrm{H}-\mathrm{NMR}$ of compound $\mathbf{5 a}$ in $\mathrm{CDCl}_{3}$. \\
\hline S14 & Figure S13: The ${ }^{13} \mathrm{C}-\mathrm{NMR}$ of compound $\mathbf{5 a}$ in $\mathrm{CDCl}_{3}$. \\
\hline S15 & Figure S14: The HR-MS of compound $\mathbf{5 a}$. \\
\hline S16 & Figure S15: The ${ }^{1} \mathrm{H}-\mathrm{NMR}$ of compound $\mathbf{5 b}$ in $\mathrm{CDCl}_{3}$. \\
\hline S17 & Figure S16: The ${ }^{13} \mathrm{C}-\mathrm{NMR}$ of compound $\mathbf{5 b}$ in $\mathrm{CDCl}_{3}$. \\
\hline S18 & Figure S17: The HR-MS of compound $\mathbf{5 b}$. \\
\hline S19 & Figure S18: The ${ }^{1} \mathrm{H}-\mathrm{NMR}$ of compound $7 \mathrm{a}$ in $\mathrm{CDCl}_{3}$. \\
\hline S20 & Figure S19: The ${ }^{1} \mathrm{H}-\mathrm{NMR}$ of compound $\mathbf{7 b}$ in $\mathrm{CDCl}_{3}$. \\
\hline S21 & Figure S2O: The ${ }^{1} \mathrm{H}-\mathrm{NMR}$ of compound $7 \mathrm{c}$ in $\mathrm{CDCl}_{3}$. \\
\hline S22 & Figure S21: The ${ }^{1} \mathrm{H}-\mathrm{NMR}$ of compound $\mathbf{7 d}$ in $\mathrm{CDCl}_{3}$. \\
\hline S23 & Figure S22: The ${ }^{1} \mathrm{H}-\mathrm{NMR}$ of compound $7 \mathrm{e}$ in $\mathrm{CDCl}_{3}$. \\
\hline S24 & Figure S23: The ${ }^{13} \mathrm{C}-\mathrm{NMR}$ of compound $7 \mathrm{e}$ in $\mathrm{CDCl}_{3}$. \\
\hline S25 & Figure S24: The HR MS of compound 7e. \\
\hline S26 & Figure S25: The ${ }^{1} \mathrm{H}-\mathrm{NMR}$ of compound $7 \mathrm{f}$ in $\mathrm{CDCl}_{3}$. \\
\hline S27 & Figure S26: The ${ }^{13} \mathrm{C}-\mathrm{NMR}$ of compound $7 \mathrm{f}$ in $\mathrm{CDCl}_{3}$. \\
\hline S28 & Figure S27: The HR-MS of compound $7 f$. \\
\hline S29 & Figure S28: The ${ }^{1} \mathrm{H}-\mathrm{NMR}$ of compound $7 \mathrm{~g}$ in $\mathrm{CDCl}_{3}$. \\
\hline S30 & Figure S29: The ${ }^{13} \mathrm{C}-\mathrm{NMR}$ of compound $7 \mathrm{~g}$ in $\mathrm{CDCl}_{3}$. \\
\hline
\end{tabular}




\begin{tabular}{|l|l|}
\hline S31 & Figure S30: The HR-MS of compound 7g. \\
\hline S32 & Figure S31: The ${ }^{1} \mathrm{H}-\mathrm{NMR}$ of compound $\mathbf{7 h}$ in $\mathrm{CDCl}_{3}$. \\
\hline S33 & Figure S32: The ${ }^{13} \mathrm{C}-\mathrm{NMR}$ of compound $\mathbf{7 h}$ in $\mathrm{CDCl}_{3}$. \\
\hline S34 & Figure S33: The HR-MS of compound $\mathbf{7 h}$. \\
\hline S35 & Figure S34: The ${ }^{1} \mathrm{H}-\mathrm{NMR}$ of compound $\mathbf{7 i}$ in $\mathrm{CDCl}_{3}$. \\
\hline S36 & Figure S35: The ${ }^{13} \mathrm{C}-\mathrm{NMR}$ of compound $\mathbf{7 i}$ in $\mathrm{CDCl}_{3}$. \\
\hline S37 & Figure S36: The HR-MS of compound $\mathbf{7 i}$. \\
\hline S38 & Figure S37: The ${ }^{1} \mathrm{H}-\mathrm{NMR}$ of compound $\mathbf{1 0}$ in $\mathrm{CDCl}_{3}$. \\
\hline S39 & Figure S38: The ${ }^{13} \mathrm{C}-\mathrm{NMR}$ of compound $\mathbf{1 0}$ in $\mathrm{CDCl}_{3}$. \\
\hline S40 & Figure S39: The HR-MS of compound $\mathbf{1 0}$. \\
\hline S41 & Figure S40: The ${ }^{1} \mathrm{H}-\mathrm{NMR}$ of compound $\mathbf{1 1}$ in $\mathrm{CD}_{3} \mathrm{OD}$. \\
\hline S42 & Figure S41: The ${ }^{13} \mathrm{C}-\mathrm{NMR}$ of compound $\mathbf{1 1}$ in $\mathrm{CD}_{3} \mathrm{OD}$. \\
\hline S43 & Figure S42: The ${ }^{13} \mathrm{C}-\mathrm{NMR}$ of compound $\mathbf{1 1}$ in $\mathrm{DMSO}_{-} \mathrm{d}_{6}$. \\
\hline S44 & Figure S43: The HR-MS of compound $\mathbf{1 1 .}$ \\
\hline S45 & Figure S44: The ${ }^{1} \mathrm{H}-\mathrm{NMR}$ of compound $\mathbf{1 2}$ in $\mathrm{CDCl}_{3}$. \\
\hline S46 & Figure S45: The ${ }^{13} \mathrm{C}-\mathrm{NMR}$ of compound $\mathbf{1 2}$ in $\mathrm{CDCl}_{3}$. \\
\hline S47 & Figure S46: The El-MS of compound $\mathbf{1 2}$. \\
\hline
\end{tabular}




\section{General Methods}

Compound 1, 4a, 4b, MeMgBr, PhMgBr, 2-methylbromobenzene, 1-bromonaphthalene, 2,6-dimethylbromobenzene, 2,6-diisopropylbromobenzene are commercially available and used as received without further purification.

THF is dried over sodium/benzoketyl still. $\mathrm{CH}_{3} \mathrm{CN}$ and $\mathrm{CH}_{2} \mathrm{Cl}_{2}$ for reactions were dried over $\mathrm{CaH}_{2}$.

Rhodamine B and fluorescein disodium salt of analytical grade were used as references for determination of fluorescence quantum yields.

\section{Molar Absorptivity and fluorescence quantum yields determinations}

First of all, measure lightly more than $10 \mathrm{mg}$ of dyes with a micro balance, which measures to $0.01 \mathrm{mg}$. This renders four significant digits to the measured weight of dyes. This dye is then dissolved in $10.00 \mathrm{~mL}$ of EtOH and the resulting solution is used as a stock for further preparation of dye solutions. The first dye solution for measurement is prepared by diluting $10.0 \mathrm{uL}$ (with a 10 uL Hamilton ${ }^{\circledR}$ air-tight micro-syringe) of this dye stock into $0.99 \mathrm{~mL}$ EtOH (for rhodamine type dyes) or $0.1 \mathrm{M} \mathrm{NaOH}$ containing $5 \% \mathrm{EtOH}$ (for 11). The absorption spectrum, excitation spectrum and the emission spectrum of the resulting solution (in a $1.4 \mathrm{~mL}$ Starna ${ }^{\circledR}$ micro-fluorescence cuvette) were acquired. We note that the excitation wavelength was chosen not to be the maximum absorbing wavelength. Rather, a slightly shorter wavelength was used to allow the entire emission band to be mapped. By the way, the same excitation wavelength was used when acquiring the emission spectra of rhodamine $B$ and the fluorescein, which are the reference dyes. Then, the dye solution was diluted by half using $\mathrm{EtOH}$ or $0.1 \mathrm{M} \mathrm{NaOH}$ with $5 \% \mathrm{EtOH}$ and the abs/ex/em of the resulting solution were acquired. Then, diluted again by half and collected abs/ex/em again. Then again and then again, until five or six sets of abs/ex/em spectra with an absorbance below 0.05 were available. The abs/em spectra from these five or six sets were used to calculate the fluorescence quantum yields.

The absorbance values were plotted against the dye concentration. The slope was calculated, which is the extinction coefficient of this dye. Then, the value is rounded to the thousand digit before included in the table 1 of the manuscript. The fluorescence quantum yield of each dye is calculated following a protocol provided in "Relative fluorescence quantum yields using a computer-controlled luminescence spectrometer" by Williams, A. T. R.; Winfield, S. A.; Miller, J. N. at Analyst, 1983,108, 1067-1071. A fluorescence quantum yield of 0.49 for Rhodamine B in EtOH, reported in J. Phys. Chem. 1988, 92, 6590-6594, was used to calculate the fluorescence quantum yields of all rhodamine dyes. A number of 0.95 in $0.1 \mathrm{M} \mathrm{NaOH}$ for fluorescein in Appl. Chem. 2011, $83,2213-2228$. was used to calculate the number of fluorescence quantum yield of compound 11. 

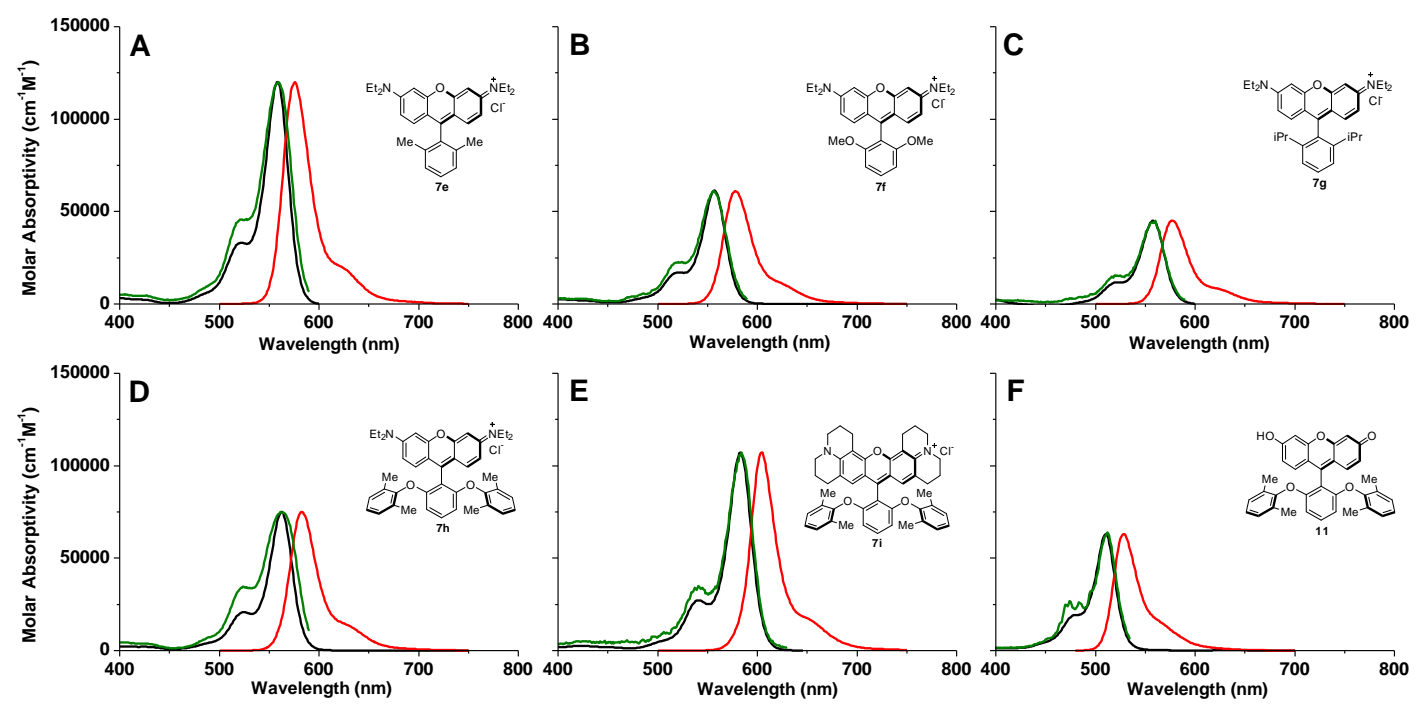

Figure S1. Absorption spectrum (Black), fluorescence excitation spectrum (Green) and fluorescence emission spectrum (Red) of dyes 7e-7i (in EtOH) and 11 (in $0.1 \mathrm{M} \mathrm{NaOH}$ ).

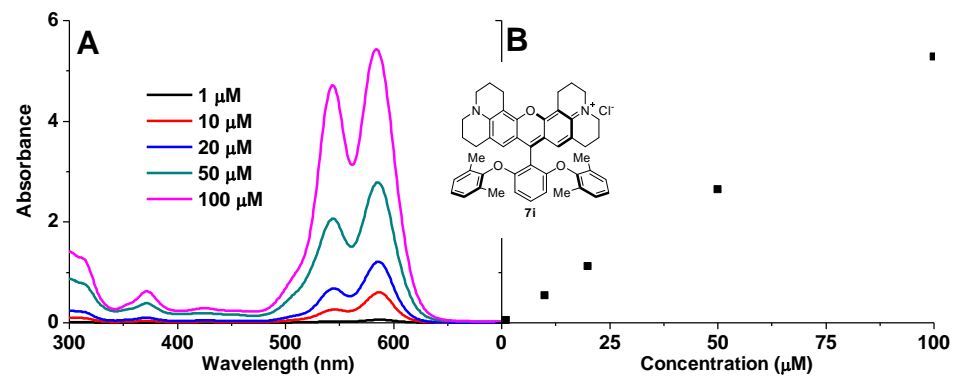

Figure S2. Aggregation study of dye $\mathbf{7 i}$, in $\mathrm{H}_{2} \mathrm{O}$ containing $5 \% \mathrm{EtOH}$, with UV-Vis spectroscopy (A). The solution absorbance is plotted against the concentration in figure $\mathrm{B}$.

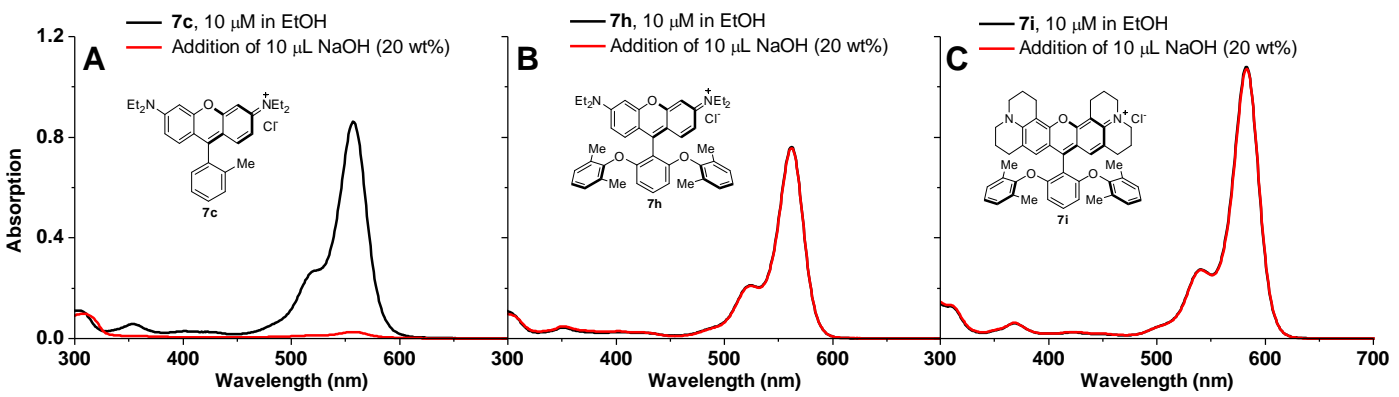

Figure S3. Chemostability study of dyes 7c (A), 7h (B) and 7i (C), as exemplified by addition of concentrated $\mathrm{NaOH}$ solution ( $20 \mathrm{wt} \%$ in $\mathrm{H}_{2} \mathrm{O}$ ) into a $10 \mu \mathrm{M}$ solution of $7 \mathrm{c}$, 7h and $7 \mathrm{i}$ in EtOH. 


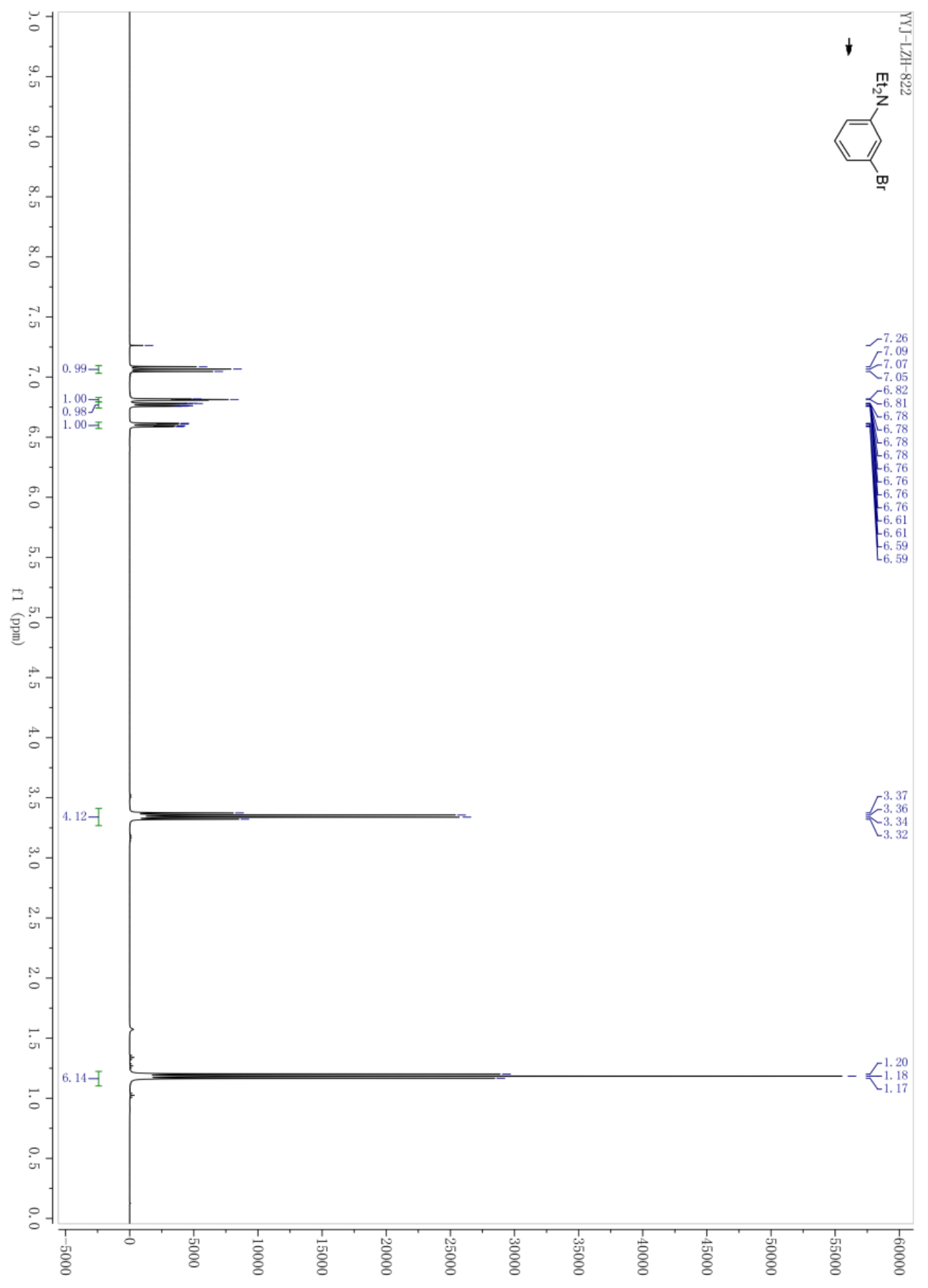

Figure S4. The ${ }^{1} \mathrm{H}-\mathrm{NMR}$ of compound $2 \mathrm{a}$ in $\mathrm{CDCl}_{3}$. 


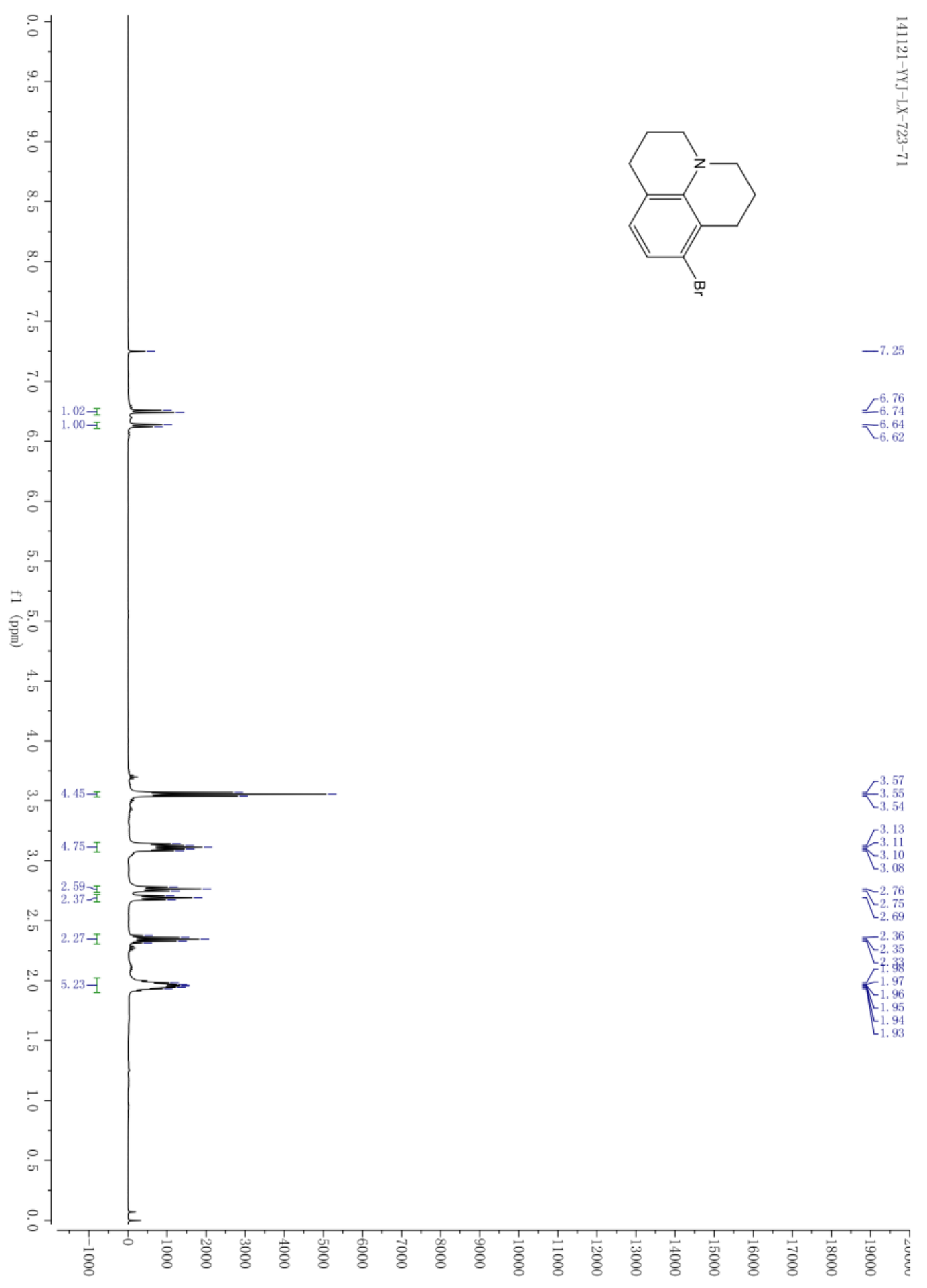

Figure $\mathrm{S} 5$. The ${ }^{1} \mathrm{H}-\mathrm{NMR}$ of compound $\mathbf{2} \mathbf{b}$ in $\mathrm{CDCl}_{3}$. 


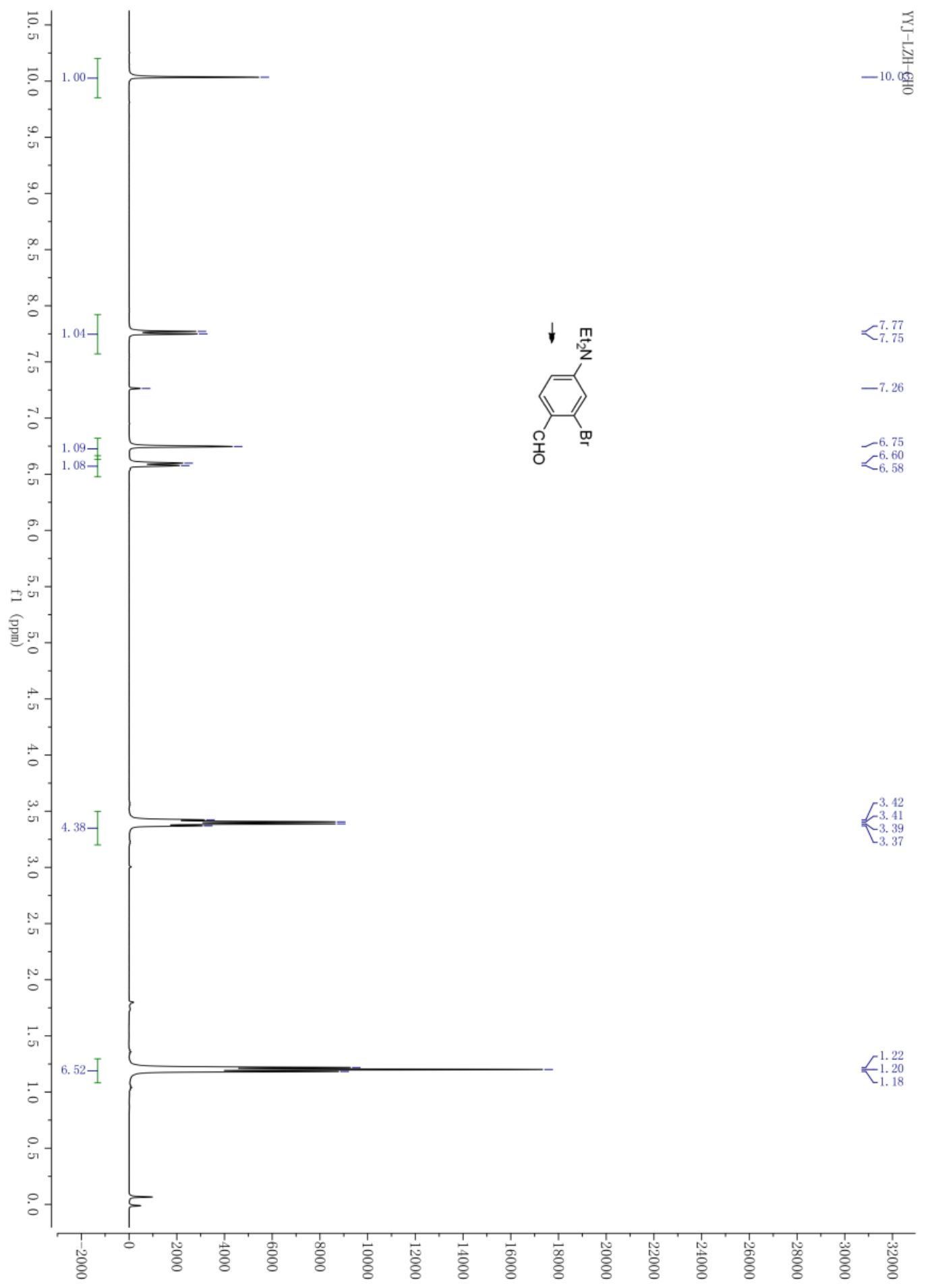

Figure S6: The ${ }^{1} \mathrm{H}-\mathrm{NMR}$ of compound $\mathbf{3 a}$ in $\mathrm{CDCl}_{3}$. 


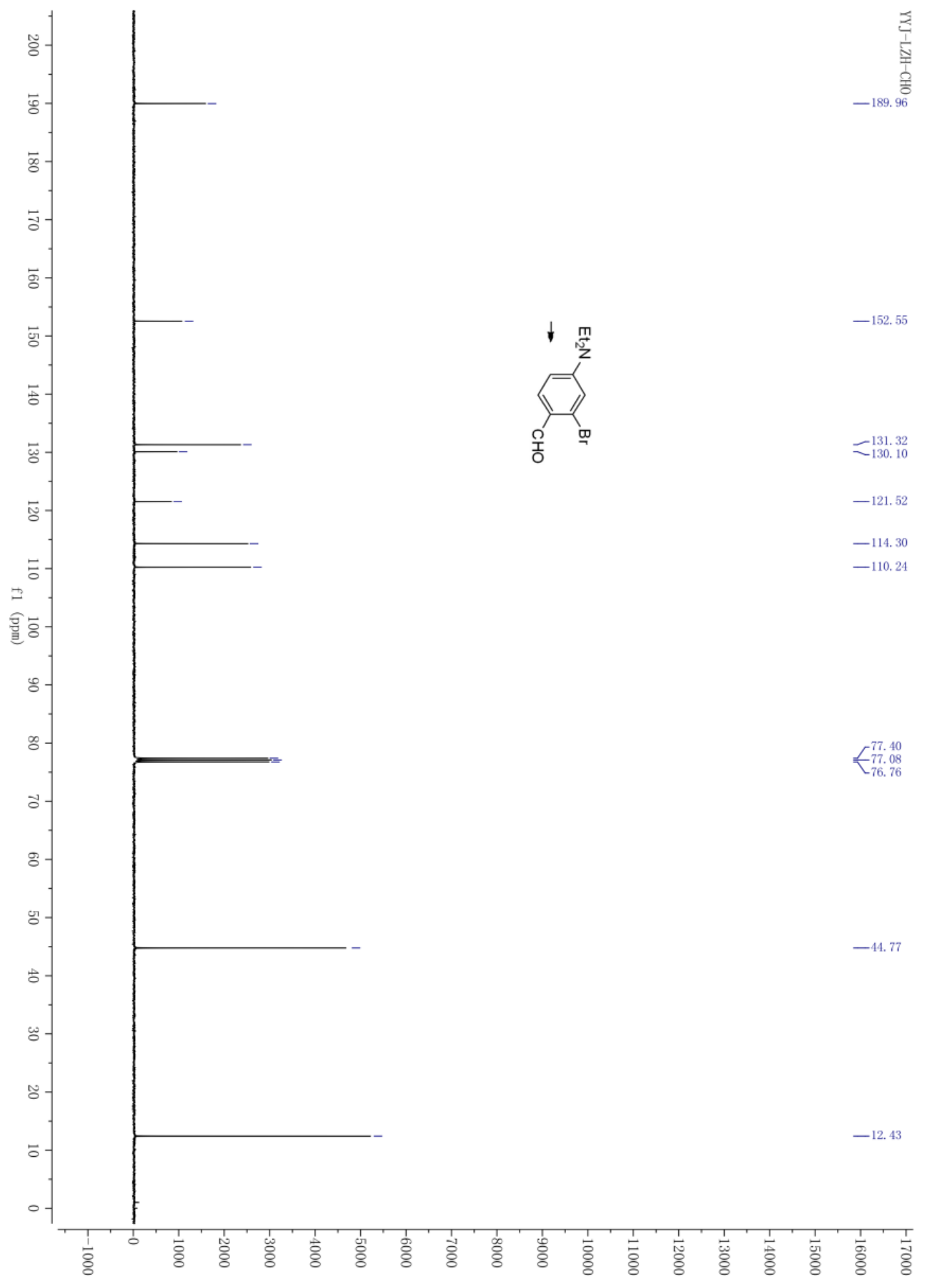

Figure S7: The ${ }^{13} \mathrm{C}-\mathrm{NMR}$ of compound $3 \mathrm{a}$ in $\mathrm{CDCl}_{3}$. 


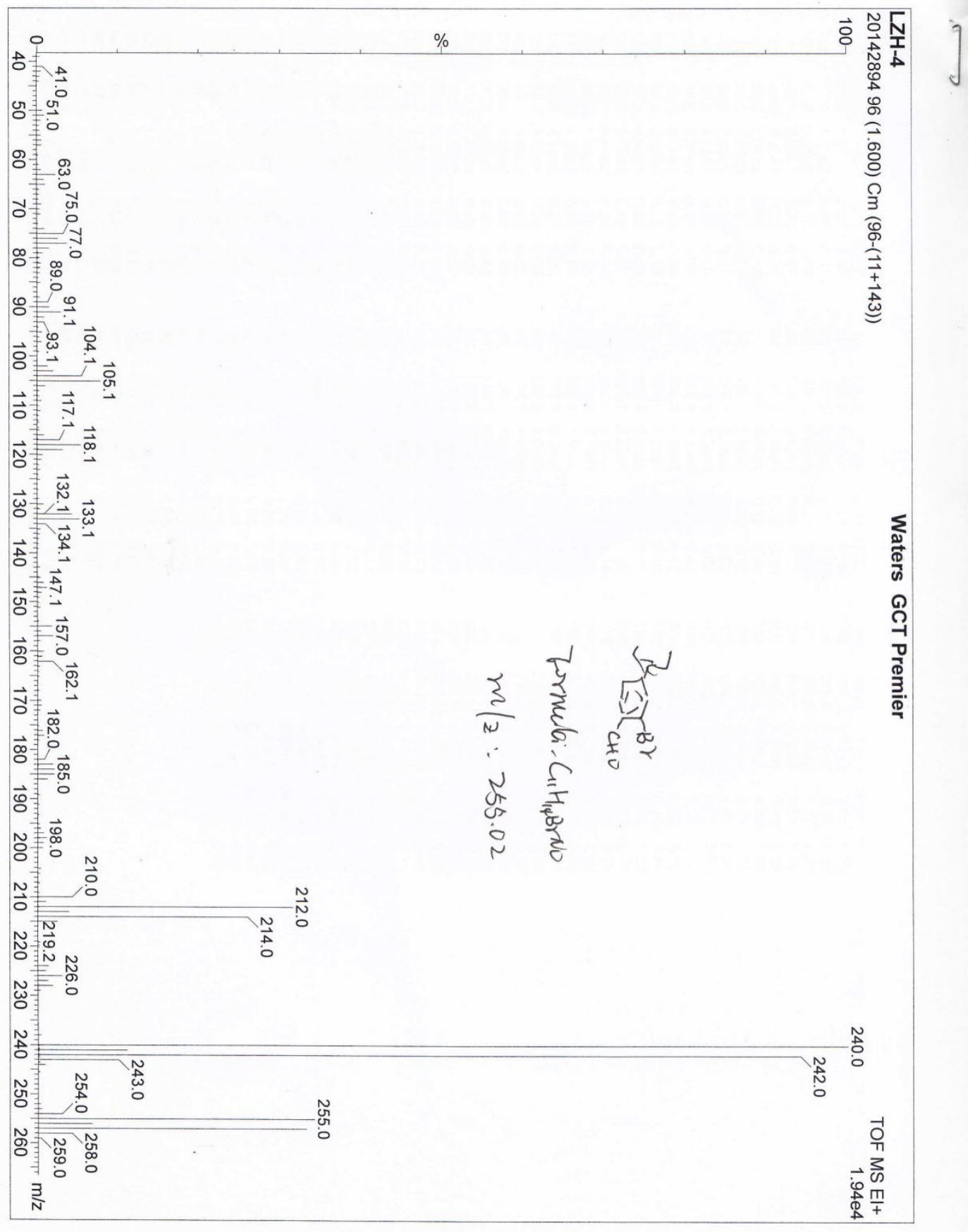

Figure S8: The EI-MS of compound 3 a. 


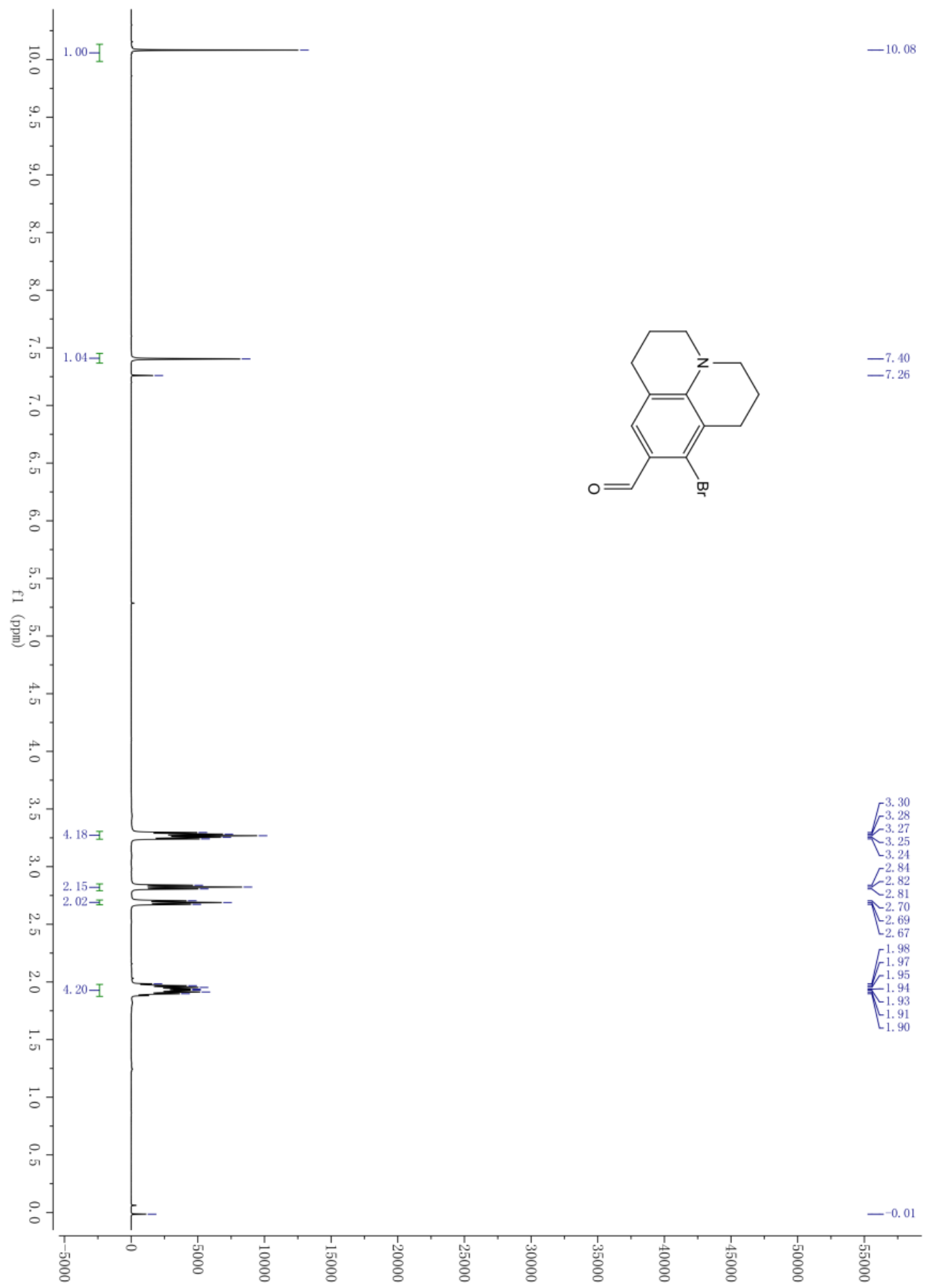

Figure S9: The ${ }^{1} \mathrm{H}-\mathrm{NMR}$ of compound $\mathbf{3 b}$ in $\mathrm{CDCl}_{3}$. 


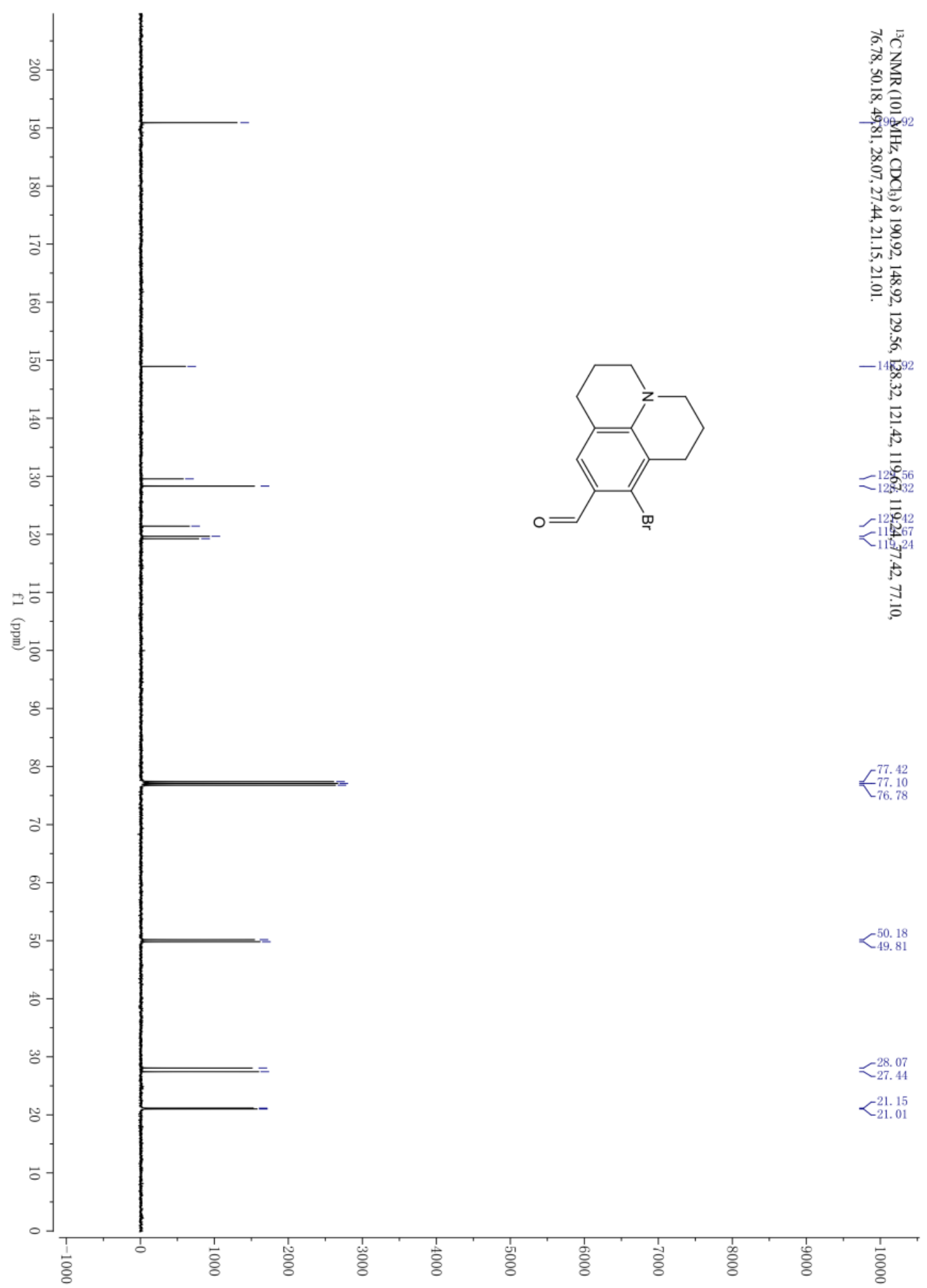

Figure S10: The ${ }^{13} \mathrm{C}-\mathrm{NMR}$ of compound $\mathbf{3 b}$ in $\mathrm{CDCl}_{3}$. 


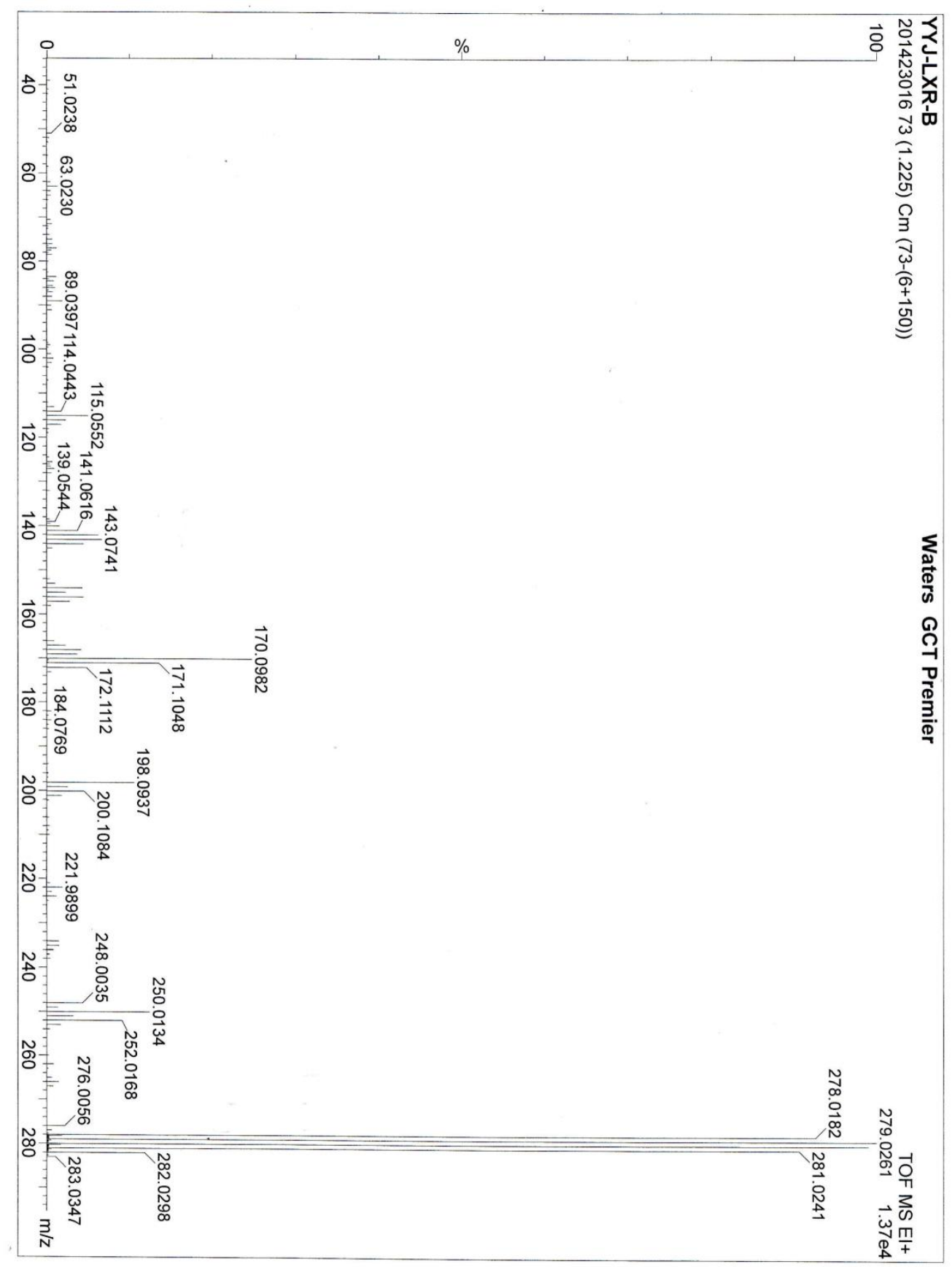

Figure S11: The HR-MS of compound $\mathbf{3 b}$. 


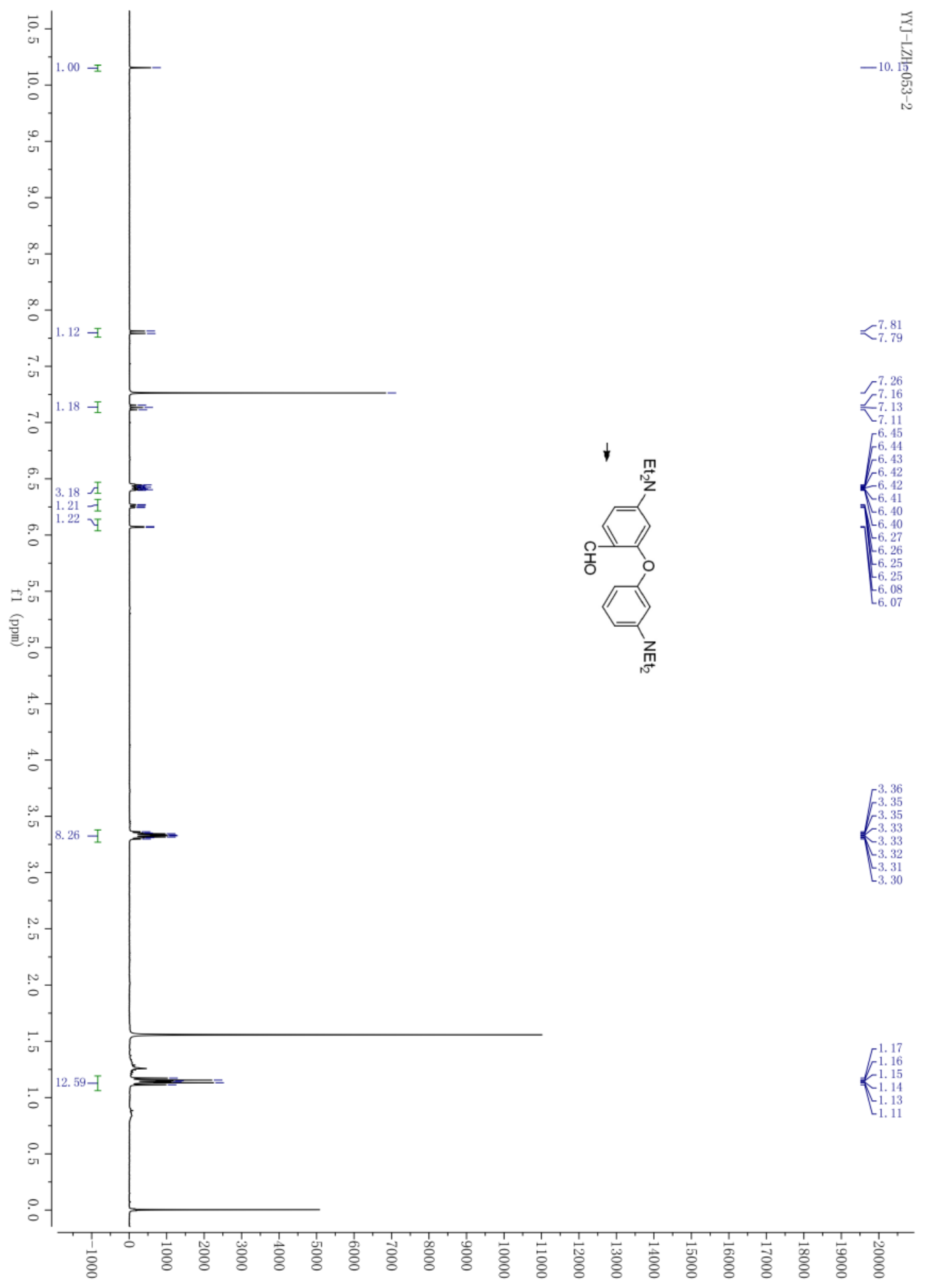

Figure S12: The ${ }^{1} \mathrm{H}-\mathrm{NMR}$ of compound $\mathbf{5 a}$ in $\mathrm{CDCl}_{3}$. 


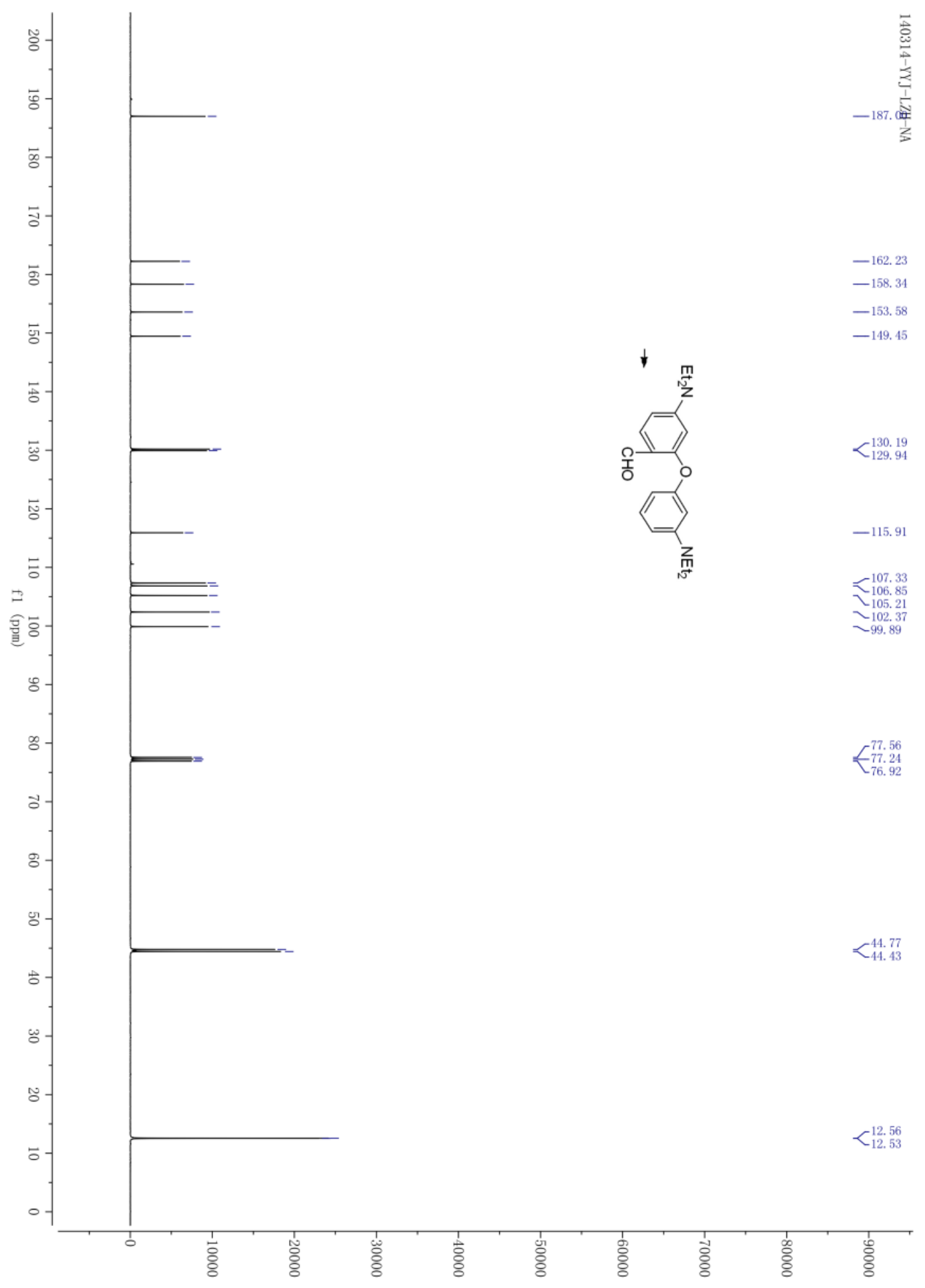

Figure S13: The ${ }^{13} \mathrm{C}-\mathrm{NMR}$ of compound $\mathbf{5 a}$ in $\mathrm{CDCl}_{3}$. 


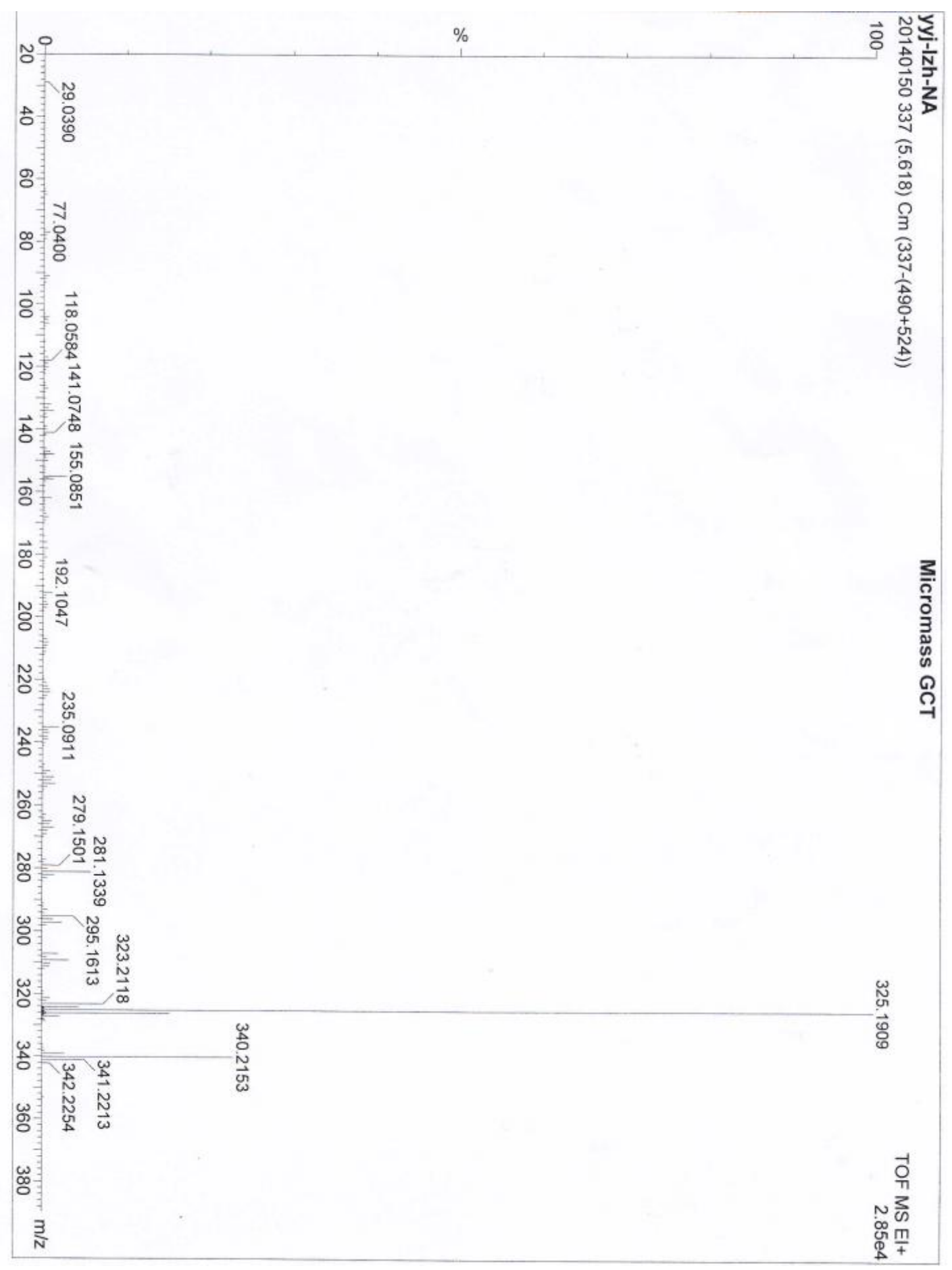

Figure S14: The HR-MS of compound 5 a. 


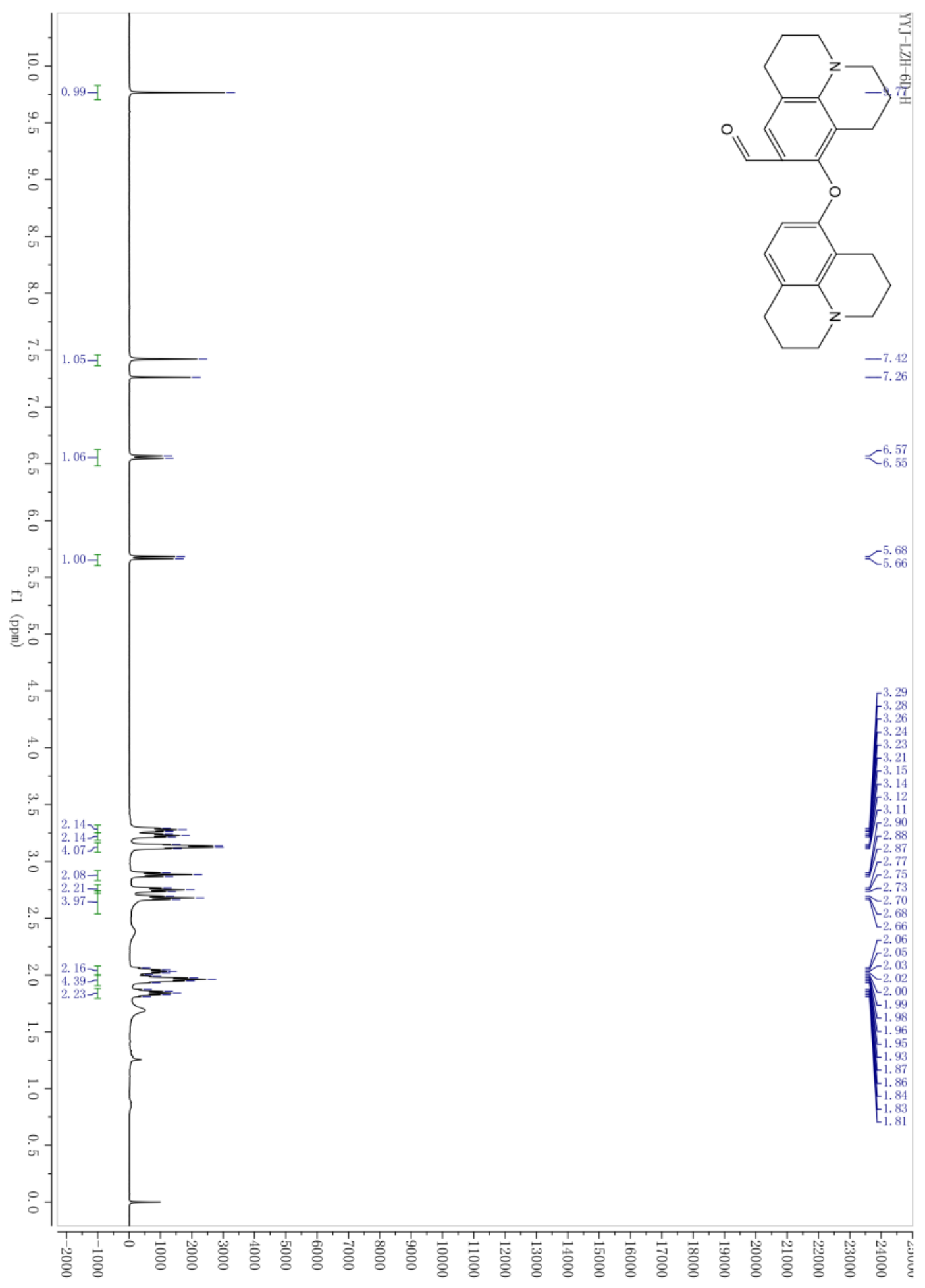

Figure S15: The ${ }^{1} \mathrm{H}-\mathrm{NMR}$ of compound $\mathbf{5 b}$ in $\mathrm{CDCl}_{3}$. 


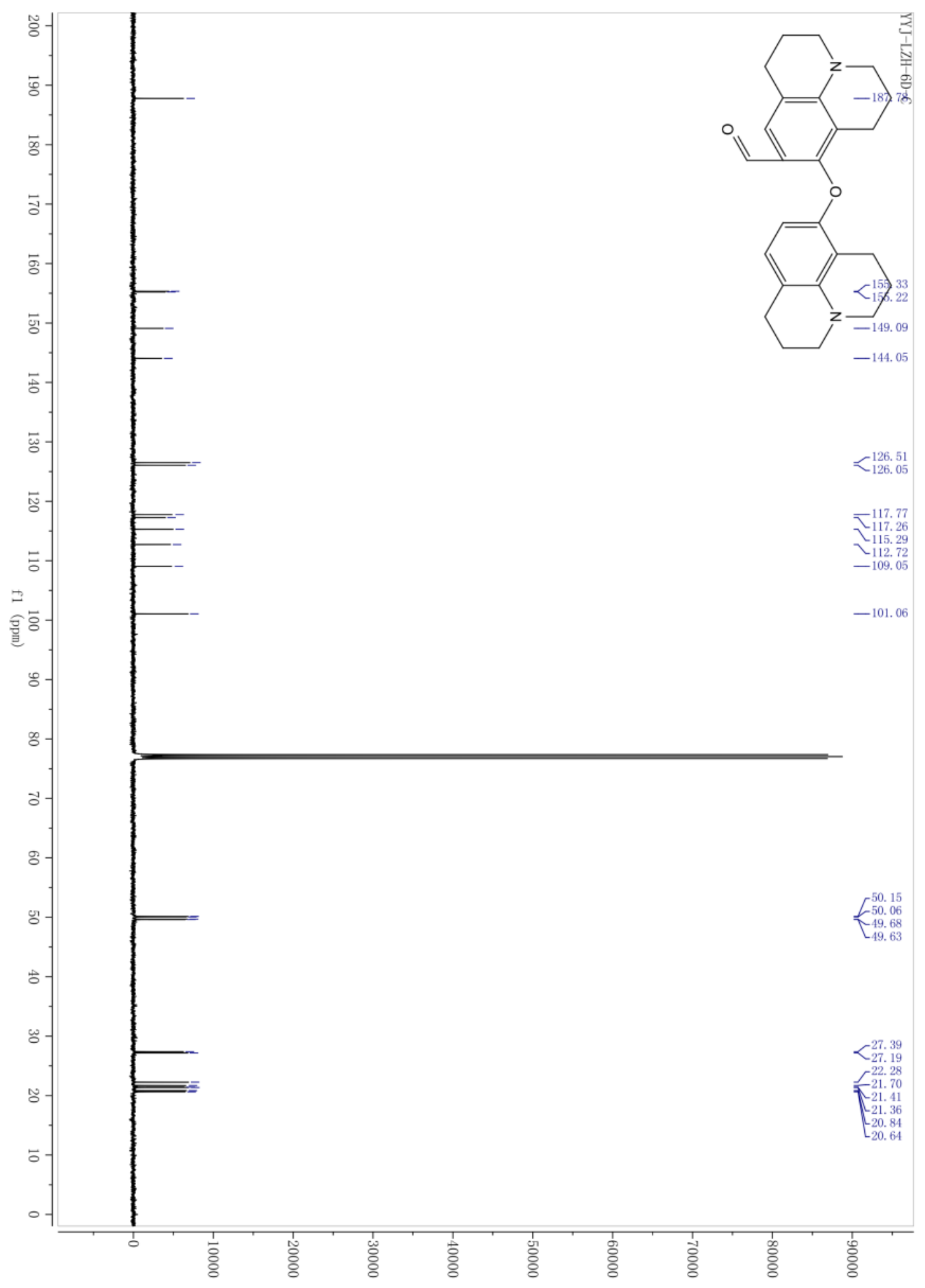

Figure S16: The ${ }^{13} \mathrm{C}-\mathrm{NMR}$ of compound $\mathbf{5 b}$ in $\mathrm{CDCl}_{3}$. 


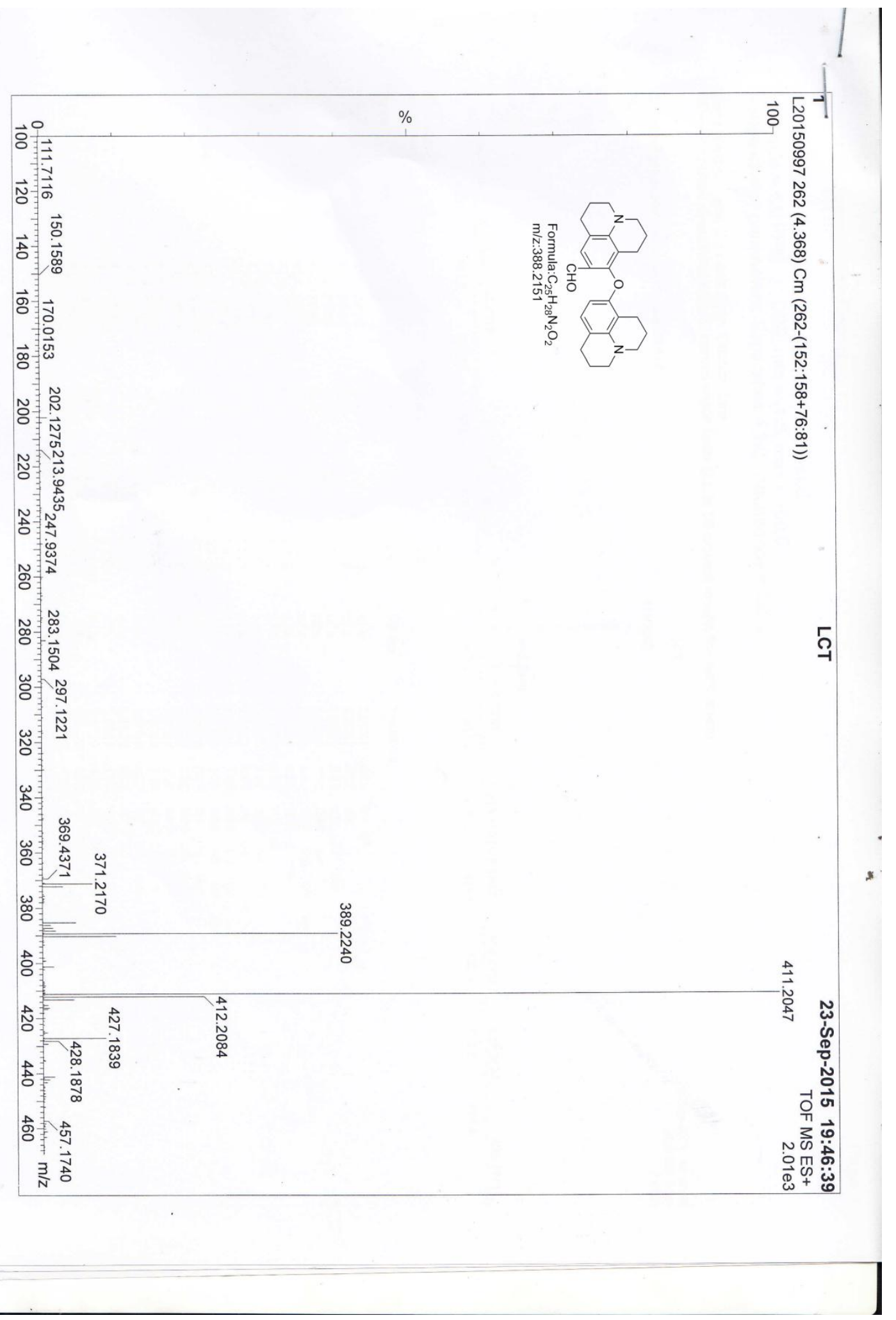

Figure S17: The HR-MS of compound $\mathbf{5 b}$. 


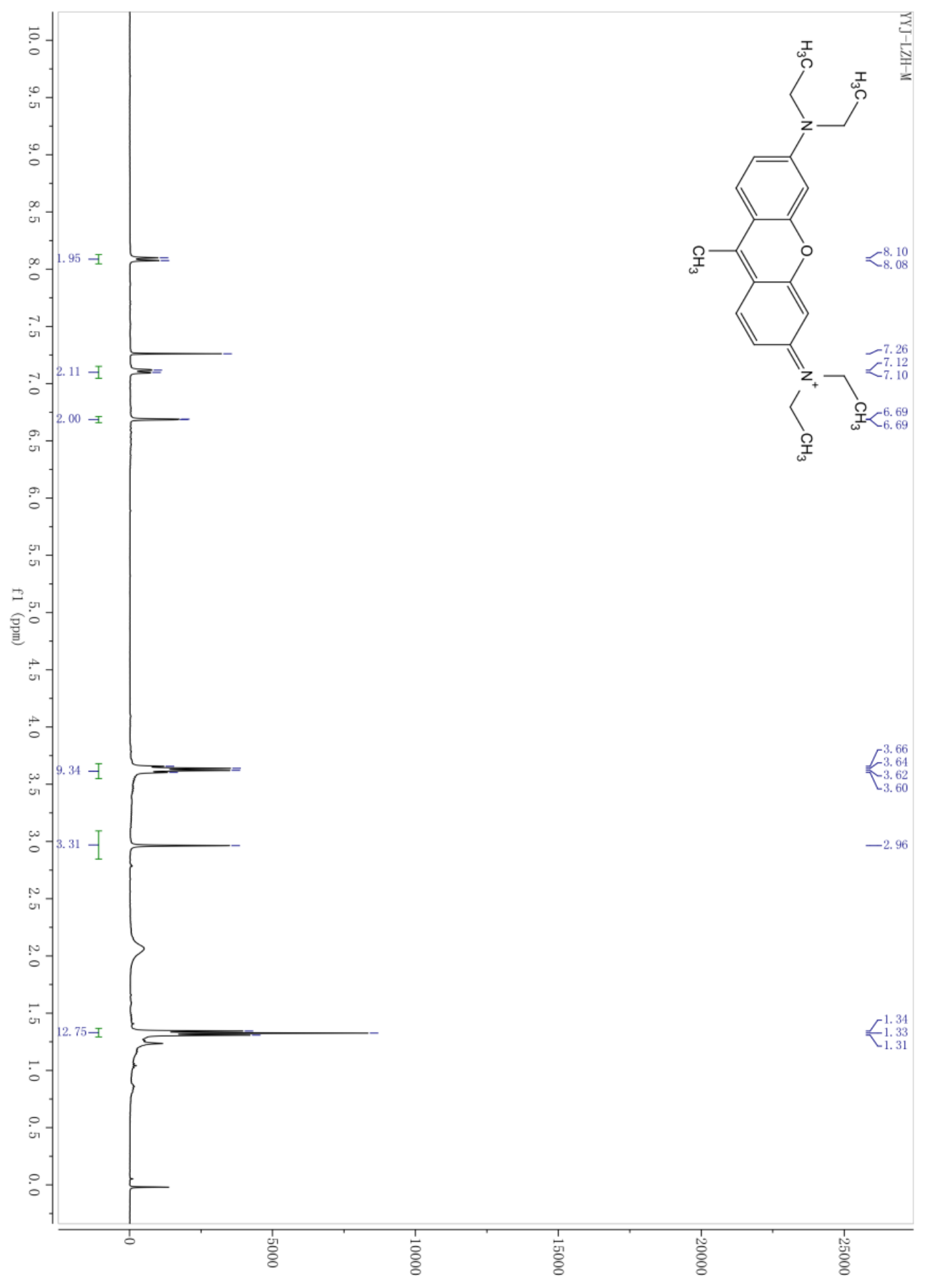

Figure S18: The ${ }^{1} \mathrm{H}-\mathrm{NMR}$ of compound $7 \mathrm{a}$ in $\mathrm{CDCl}_{3}$. 


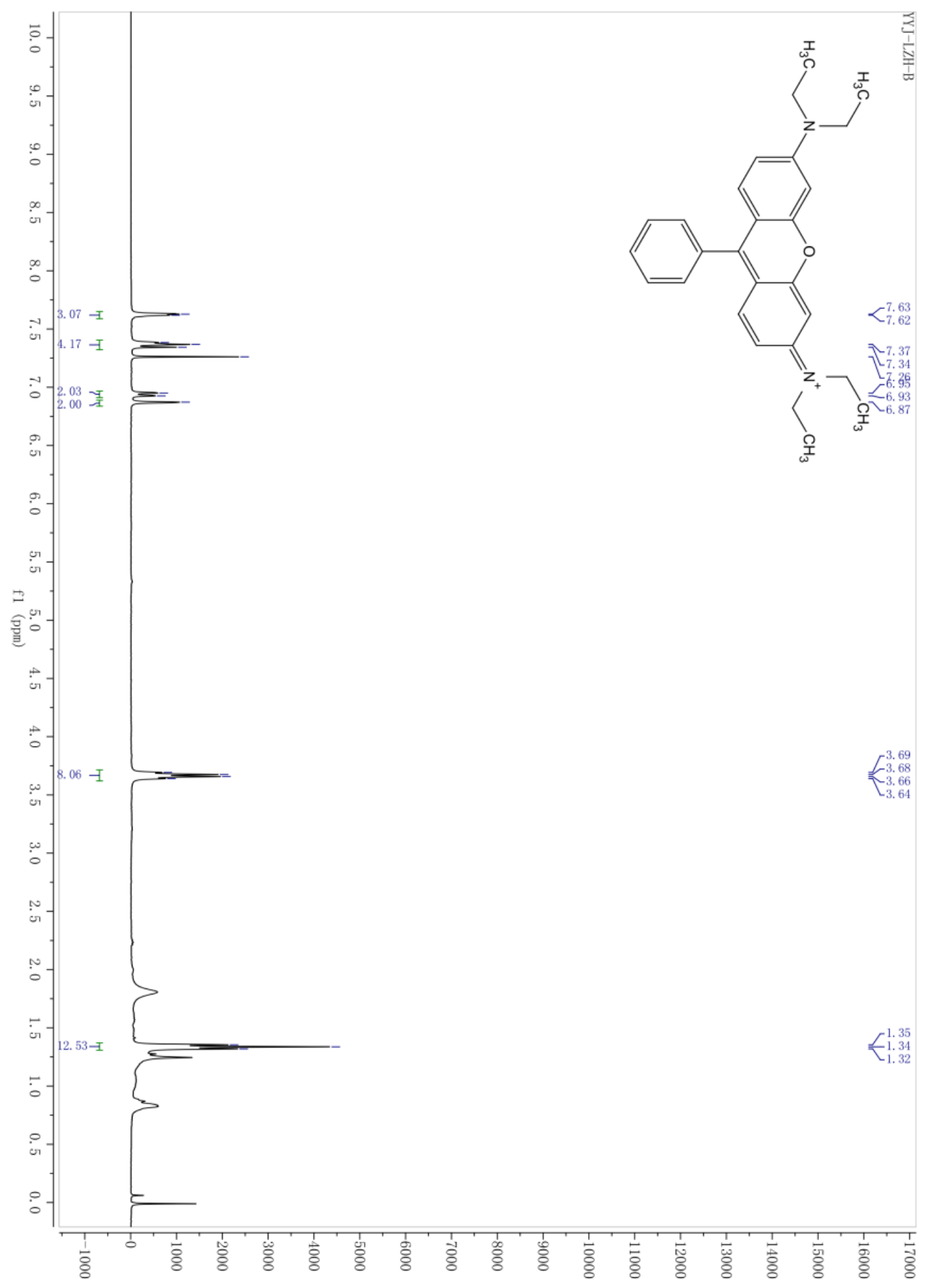

Figure S19: The ${ }^{1} \mathrm{H}-\mathrm{NMR}$ of compound $\mathbf{7 b}$ in $\mathrm{CDCl}_{3}$. 


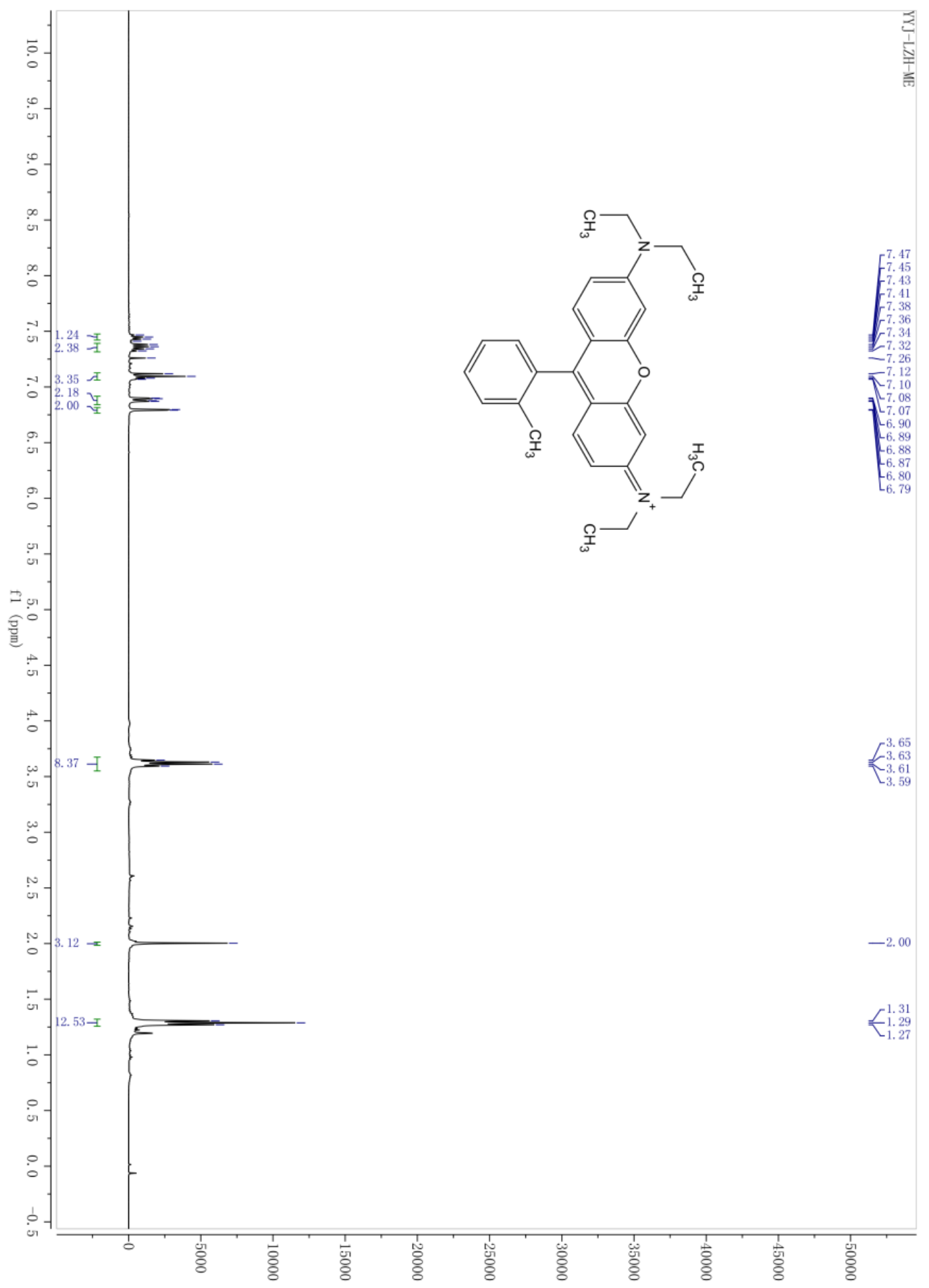

Figure S20: The ${ }^{1} \mathrm{H}-\mathrm{NMR}$ of compound $7 \mathrm{c}$ in $\mathrm{CDCl}_{3}$. 


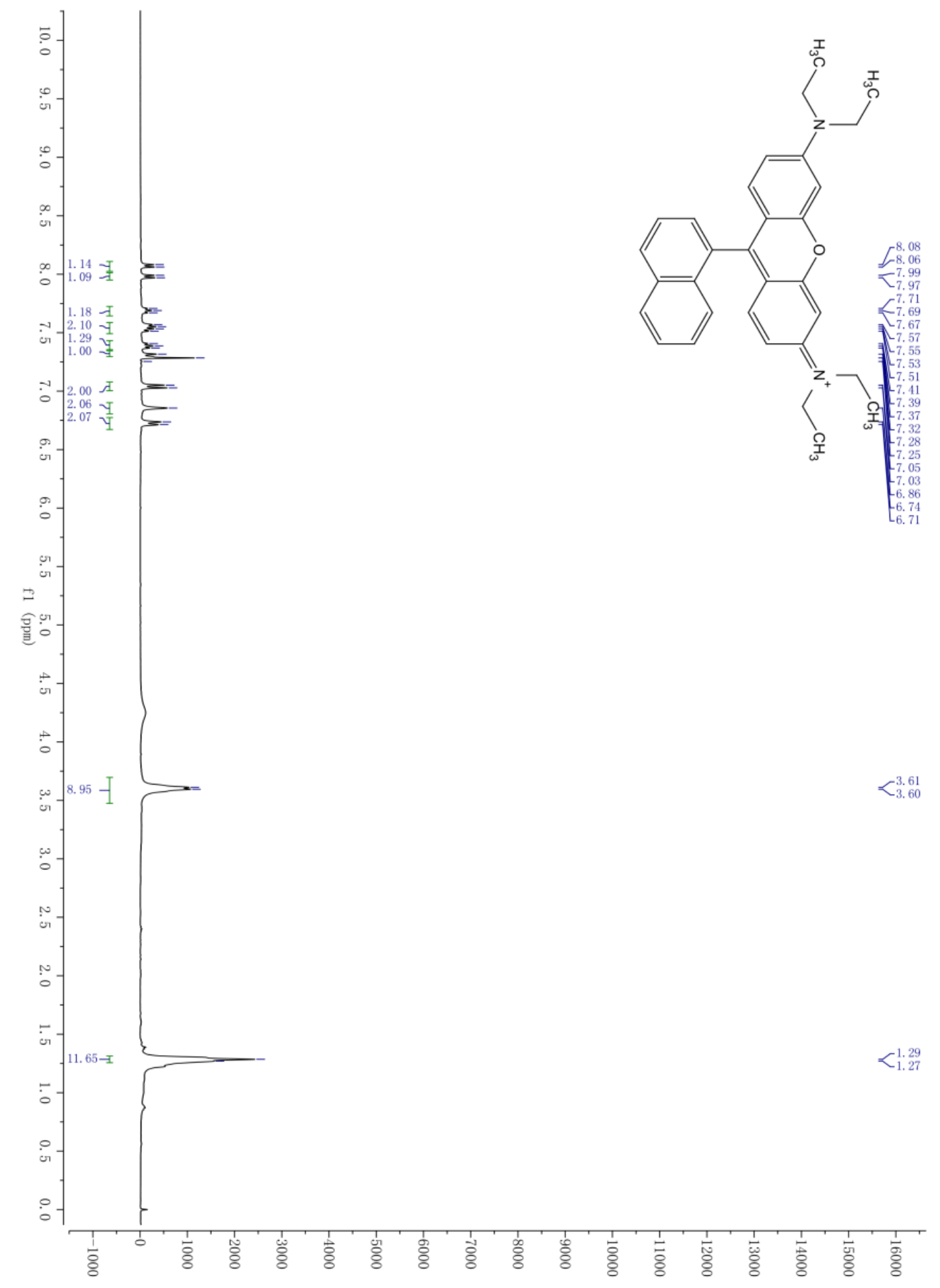

Figure S21: The ${ }^{1} \mathrm{H}-\mathrm{NMR}$ of compound $\mathbf{7 d}$ in $\mathrm{CDCl}_{3}$. 


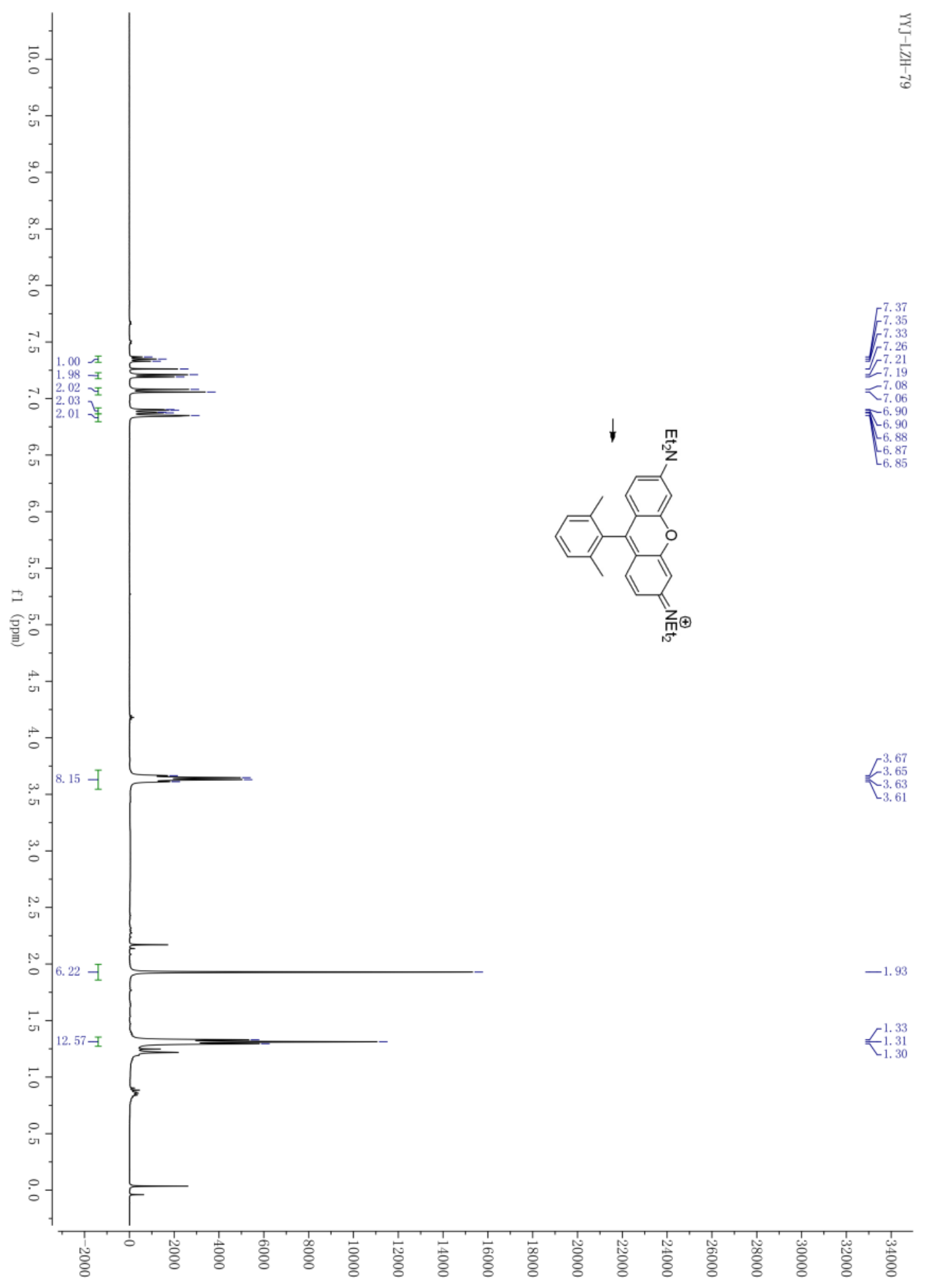

Figure S22: The ${ }^{1} \mathrm{H}-\mathrm{NMR}$ of compound $7 \mathrm{e}$ in $\mathrm{CDCl}_{3}$. 


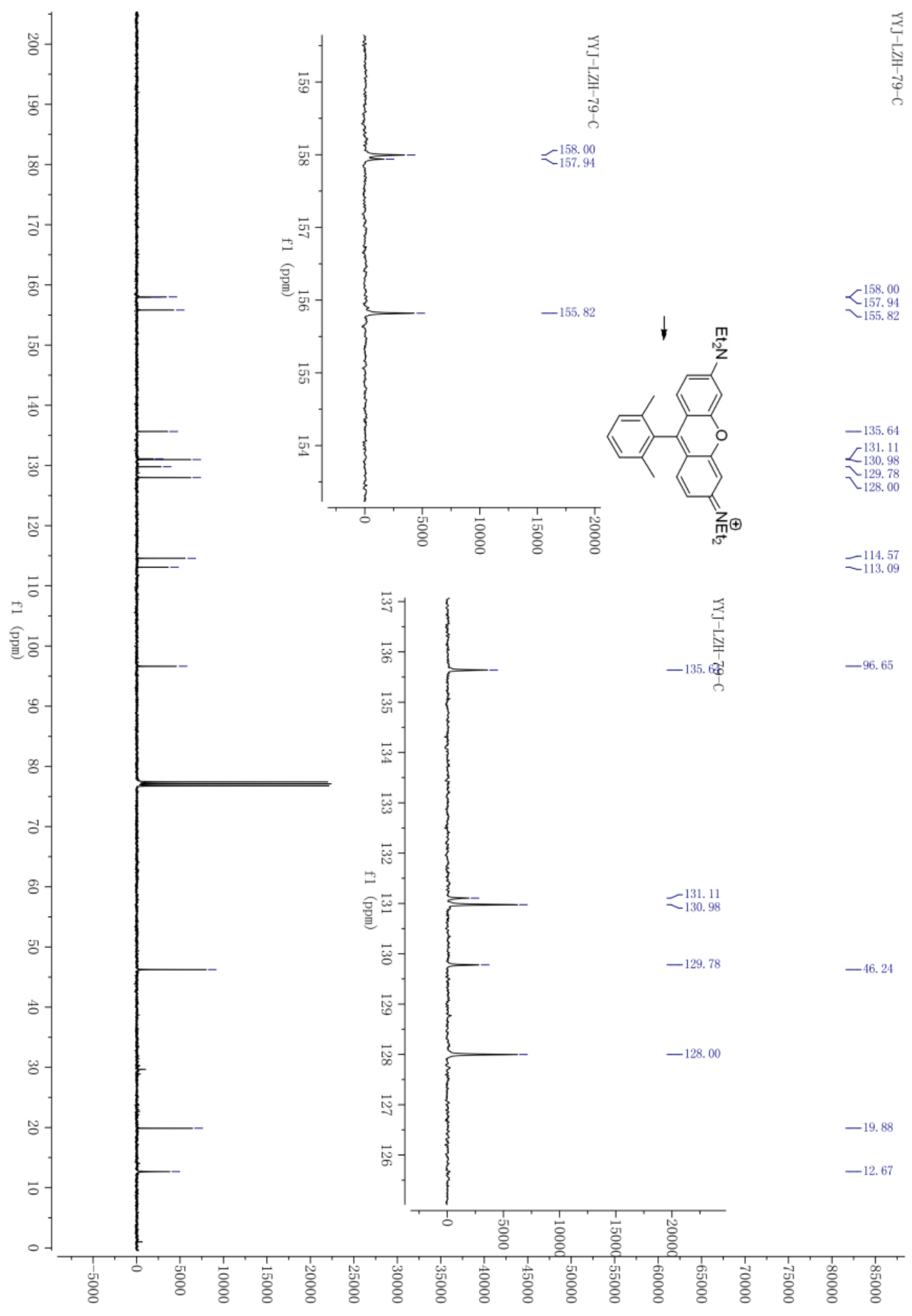

Figure S23: The ${ }^{13} \mathrm{C}-\mathrm{NMR}$ of compound $\mathbf{7 e}$ in $\mathrm{CDCl}_{3}$. 


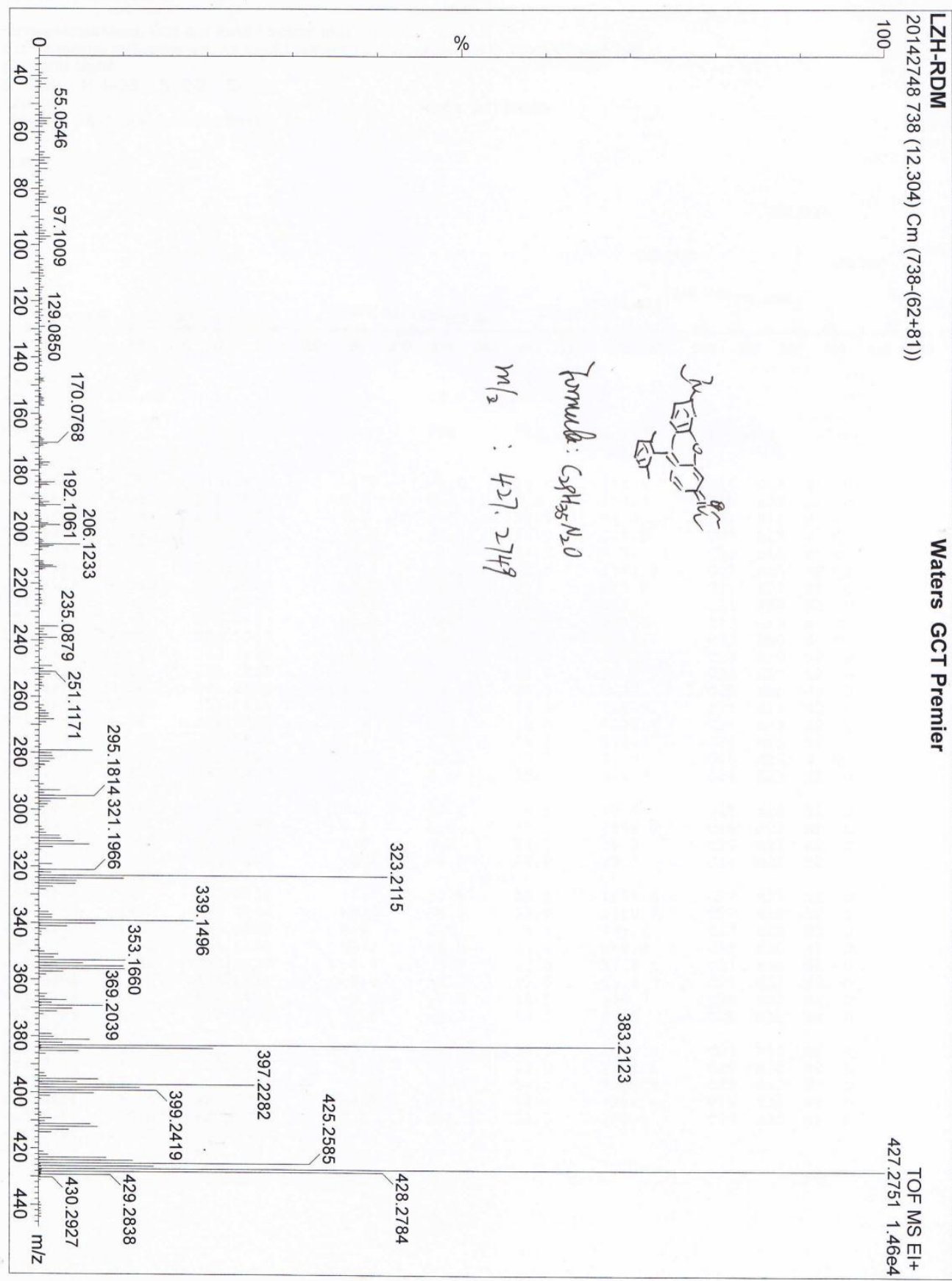

Figure S24: The HR MS of compound 7e. 


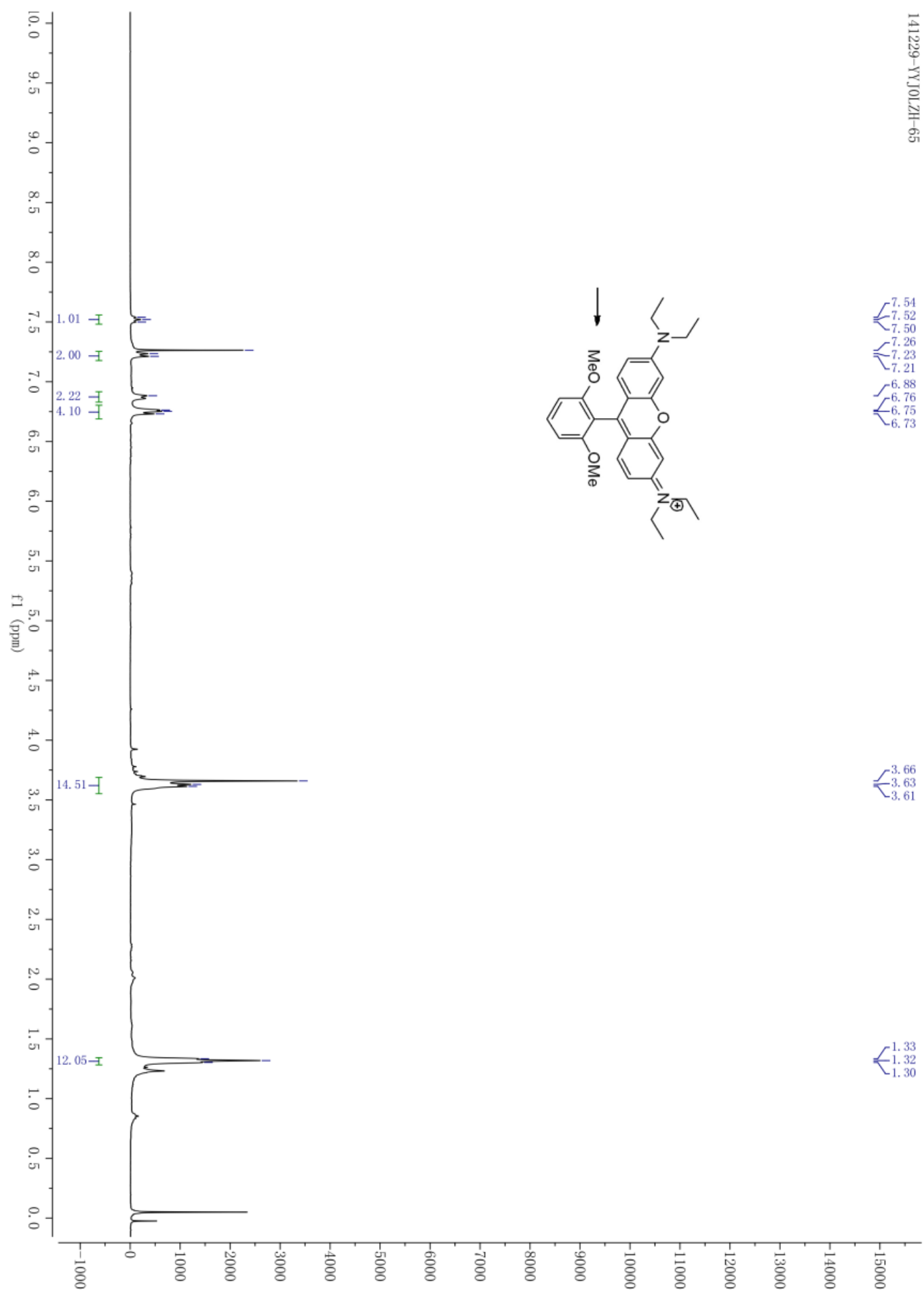

Figure S25: The ${ }^{1} \mathrm{H}-\mathrm{NMR}$ of compound $7 \mathrm{f}$ in $\mathrm{CDCl}_{3}$. 


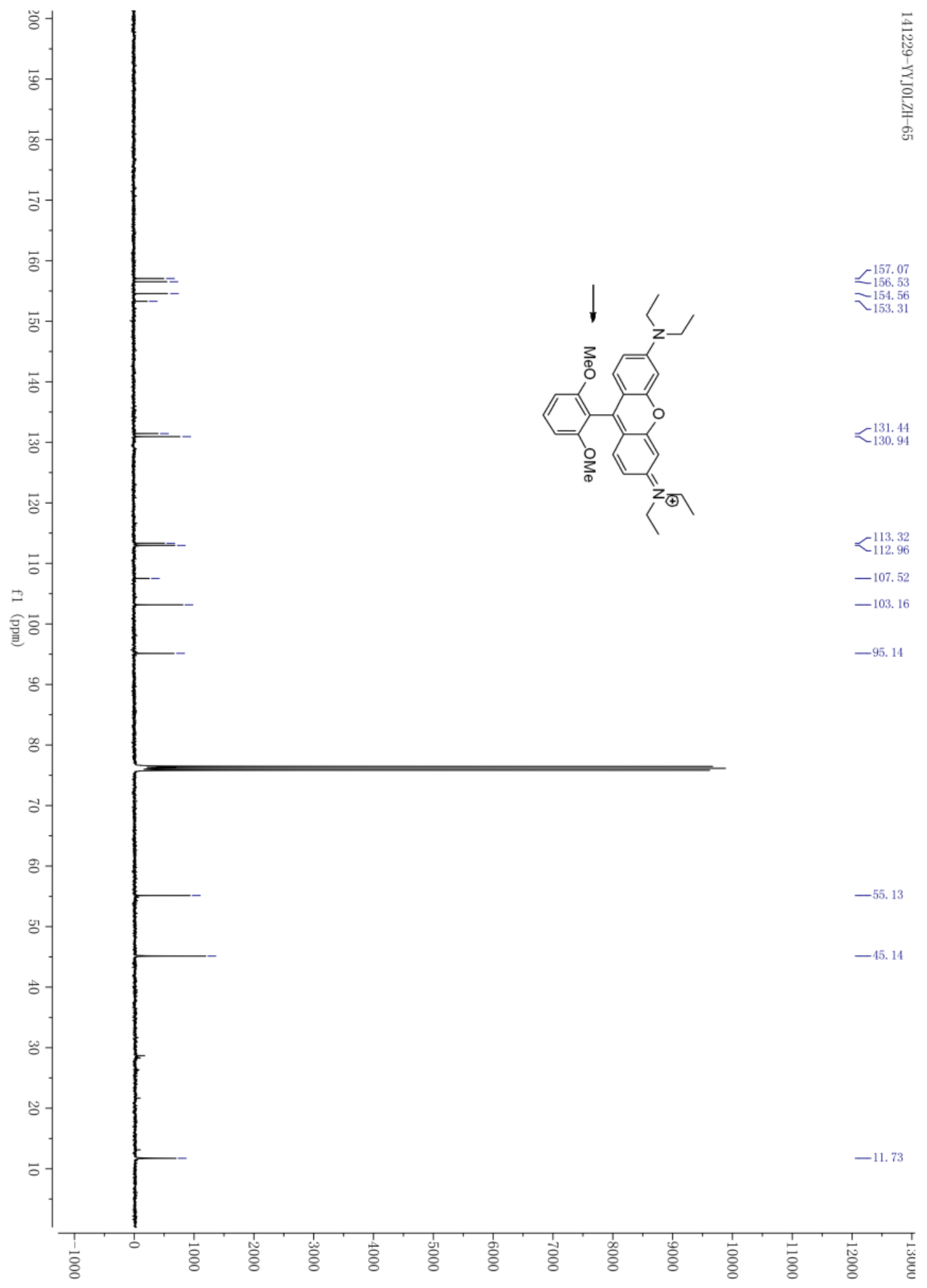

Figure S26: The ${ }^{13} \mathrm{C}-\mathrm{NMR}$ of compound $7 \mathrm{f}$ in $\mathrm{CDCl}_{3}$. 


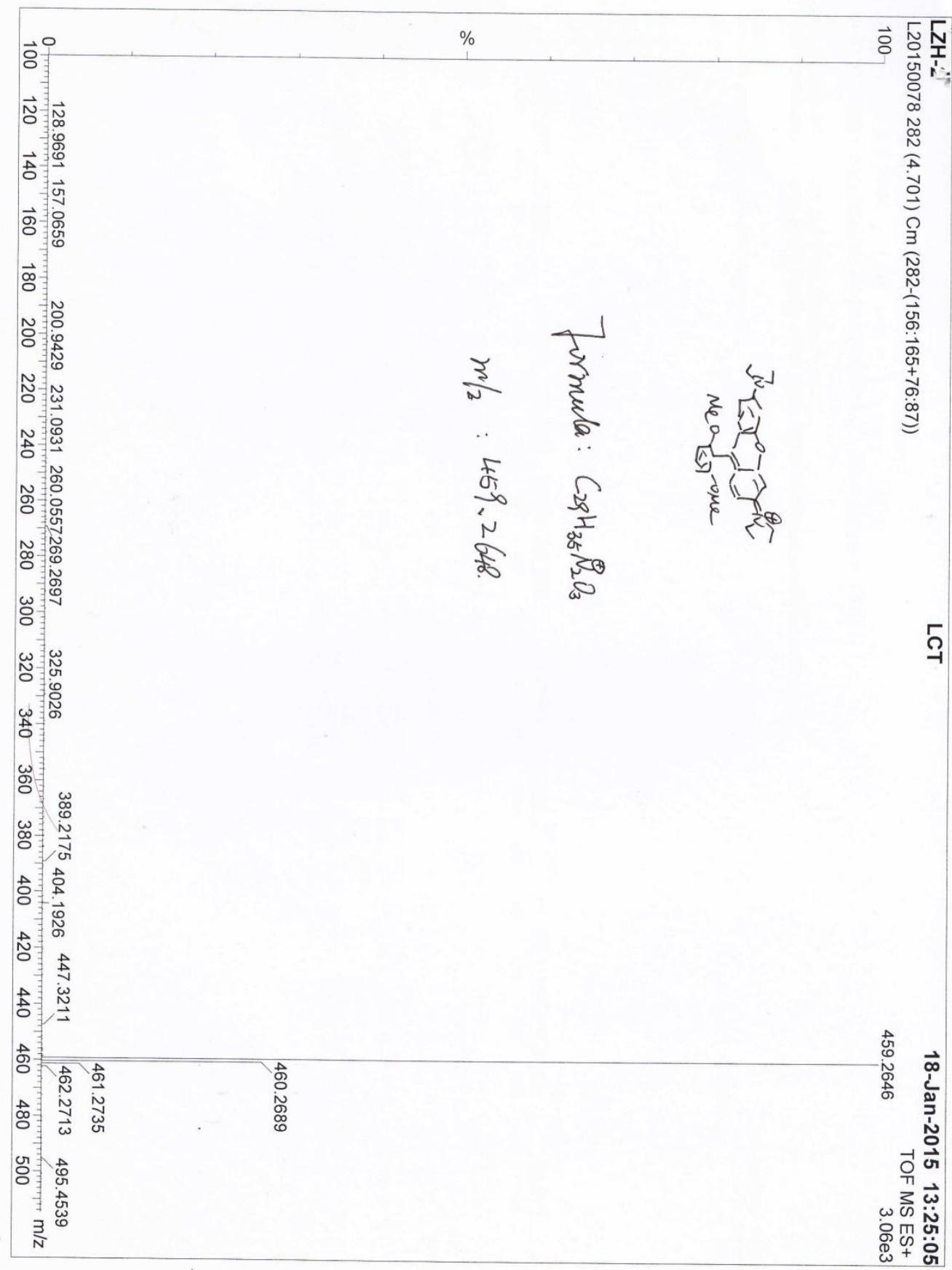

Figure S27: The HR-MS of compound $7 f$. 


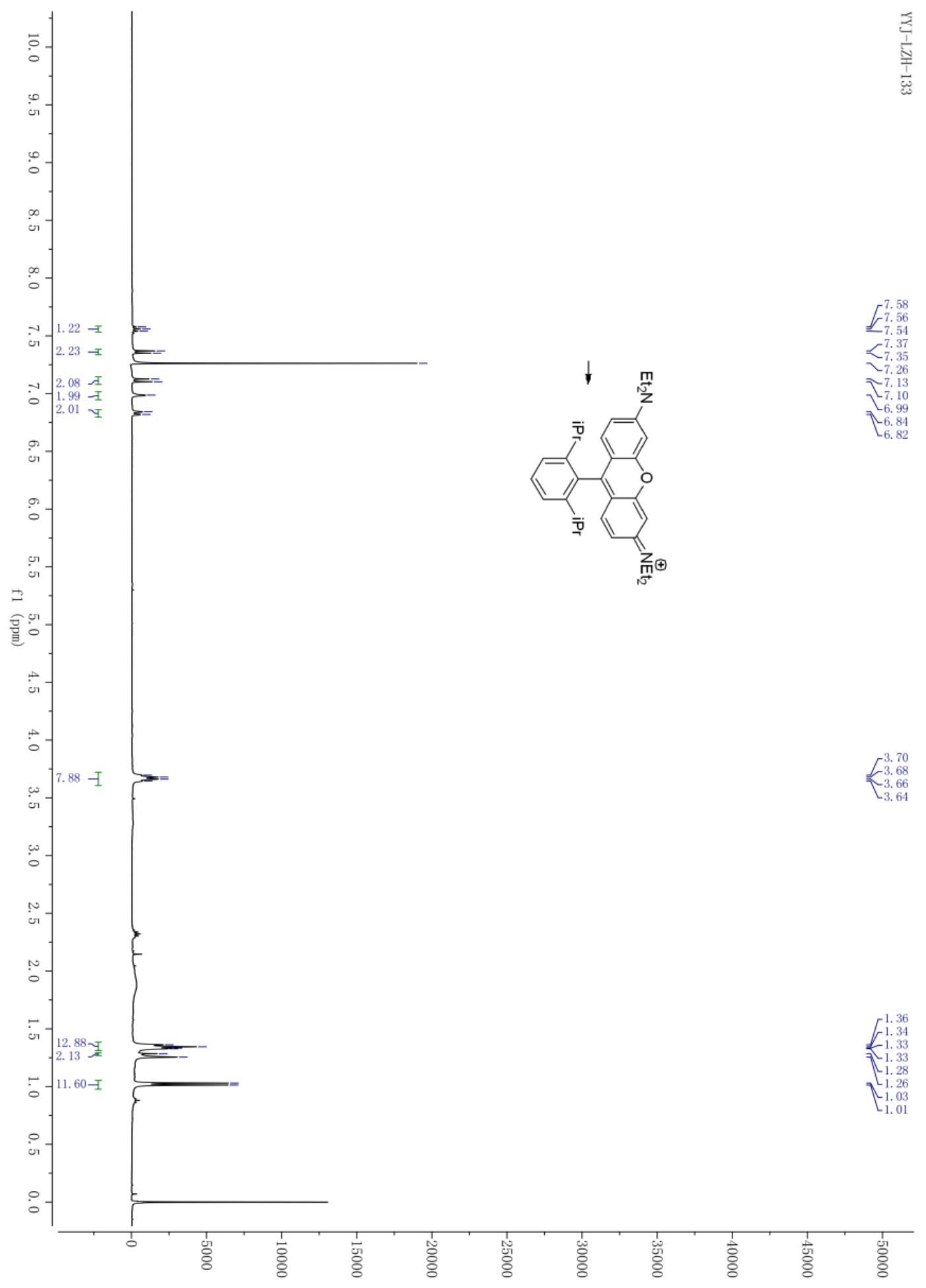

Figure S28: The ${ }^{1} \mathrm{H}-\mathrm{NMR}$ of compound $\mathbf{7 g}$ in $\mathrm{CDCl}_{3}$. 


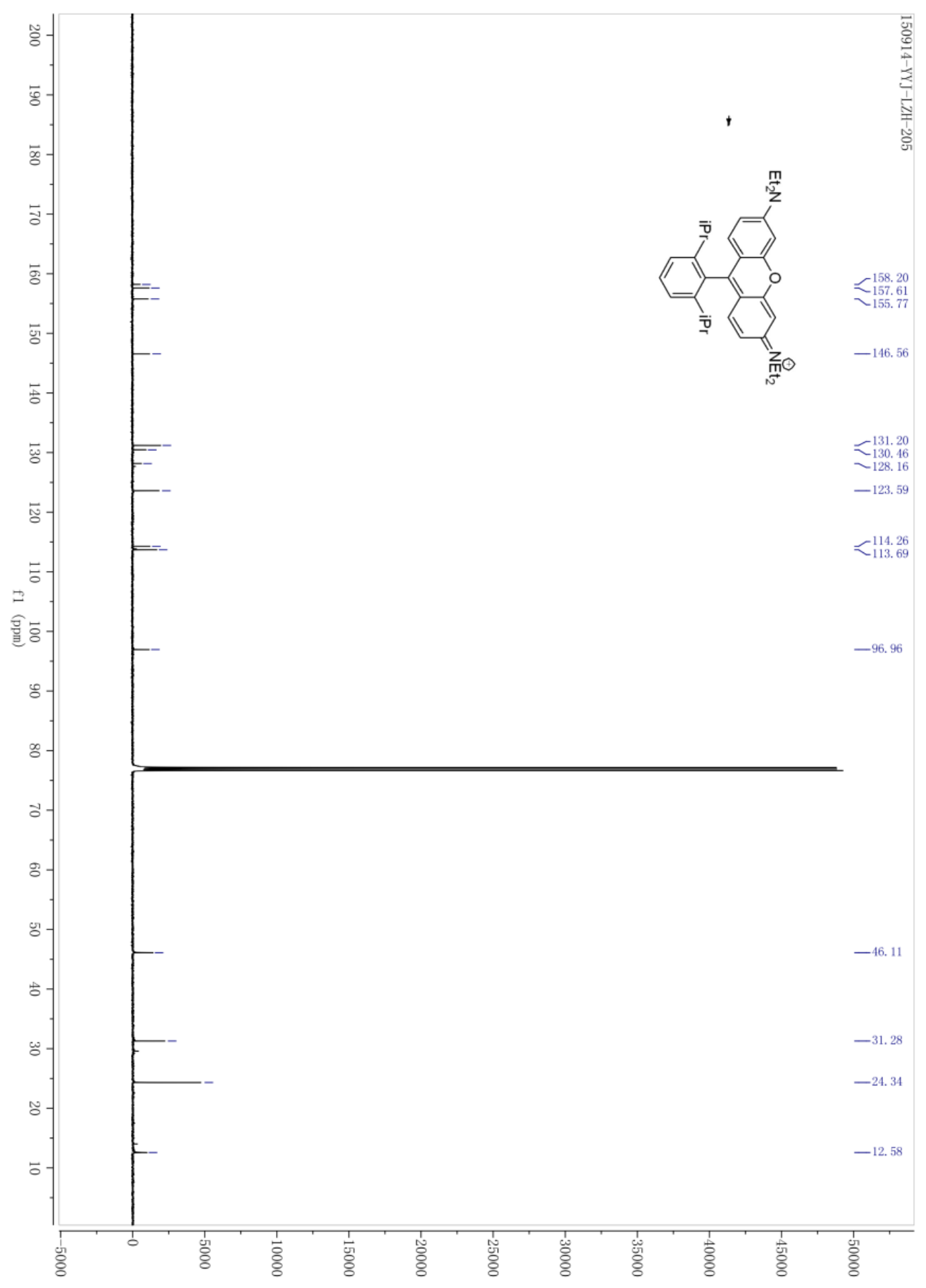

Figure S29: The ${ }^{13} \mathrm{C}-\mathrm{NMR}$ of compound $\mathbf{7 g}$ in $\mathrm{CDCl}_{3}$. 


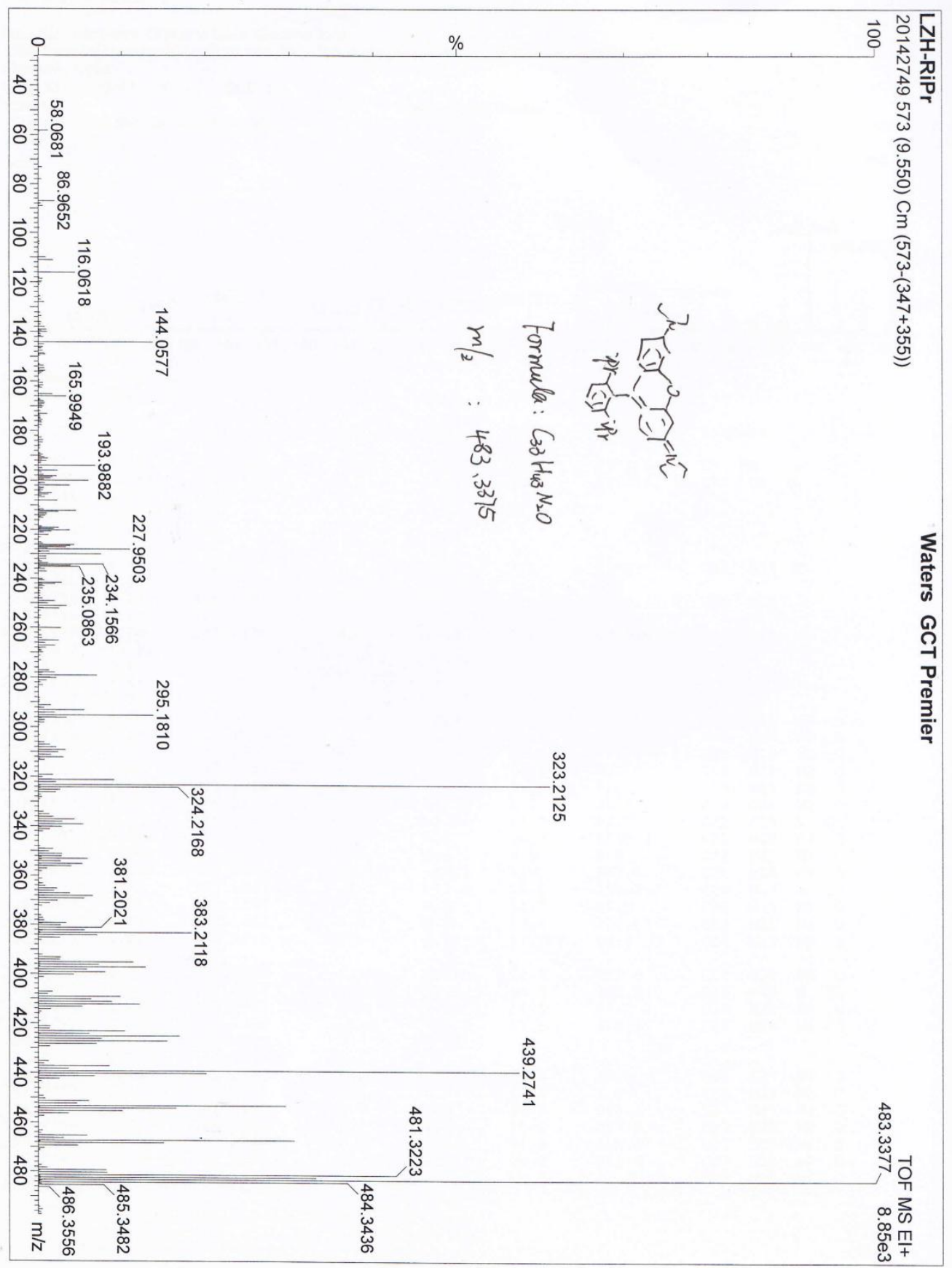

Figure S30: The HR-MS of compound 7g. 


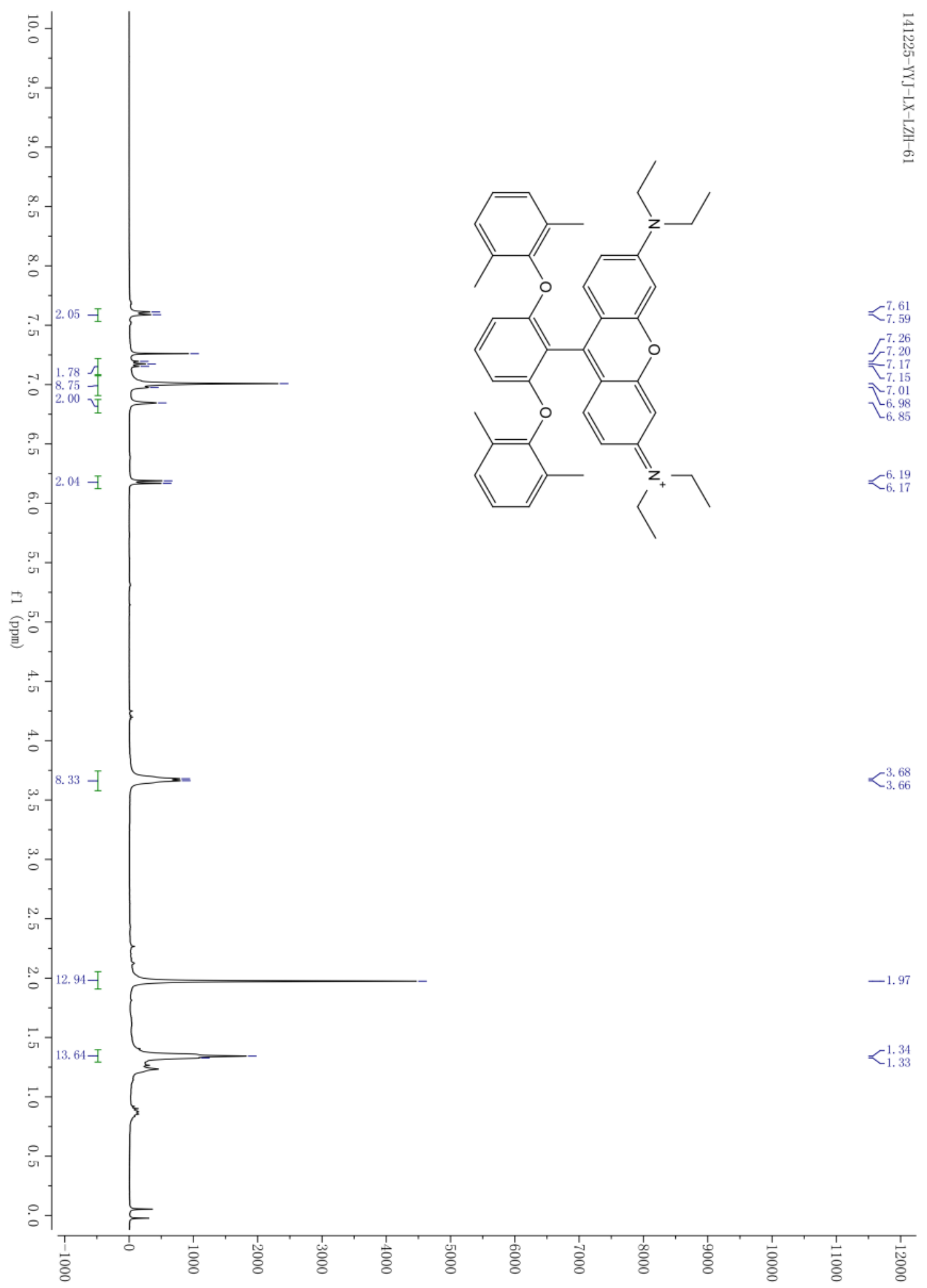

Figure S31: The ${ }^{1} \mathrm{H}-\mathrm{NMR}$ of compound $7 \mathrm{~h}$ in $\mathrm{CDCl}_{3}$. 


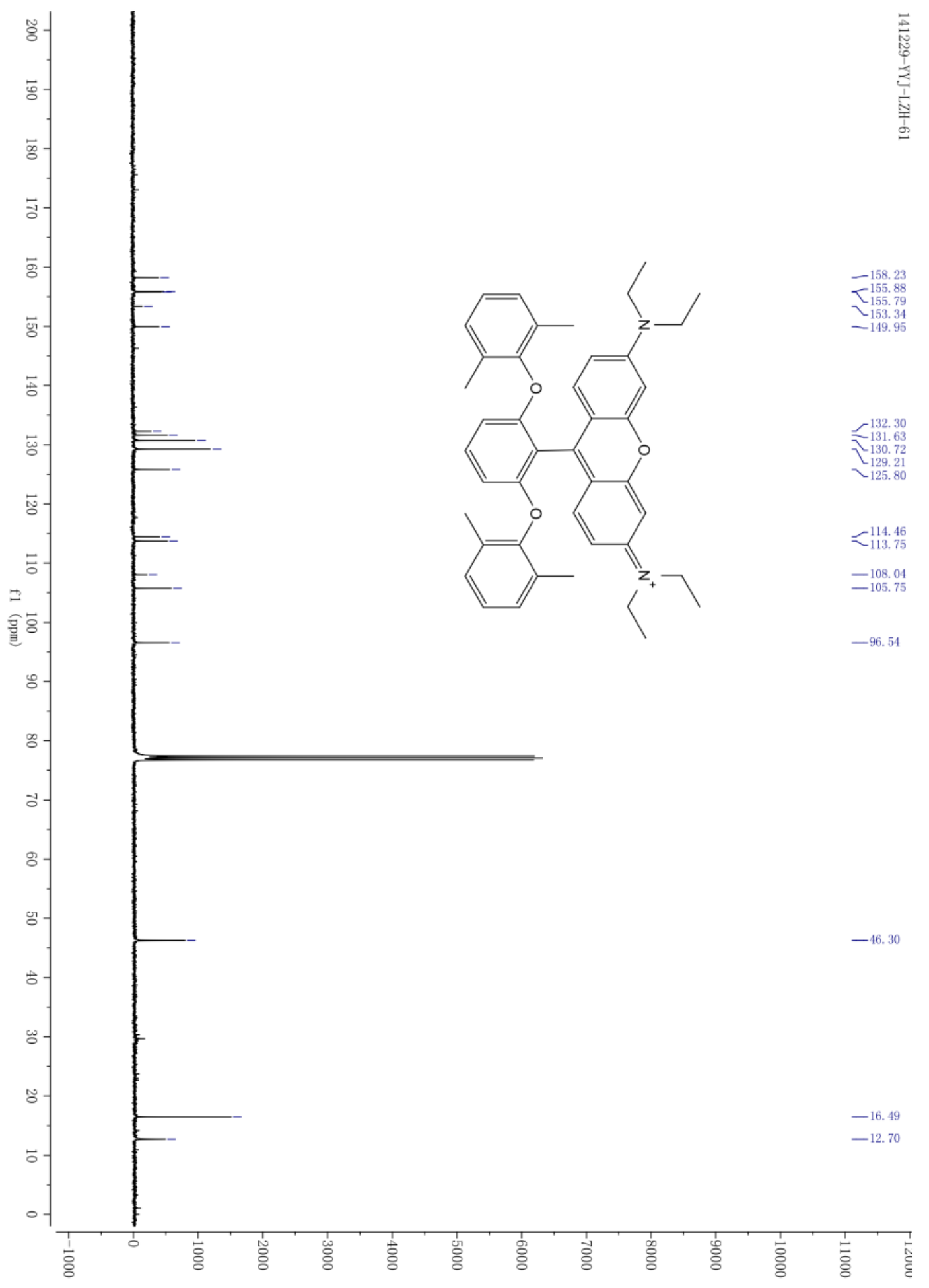

Figure S32: The ${ }^{13} \mathrm{C}-\mathrm{NMR}$ of compound $\mathbf{7 h}$ in $\mathrm{CDCl}_{3}$. 


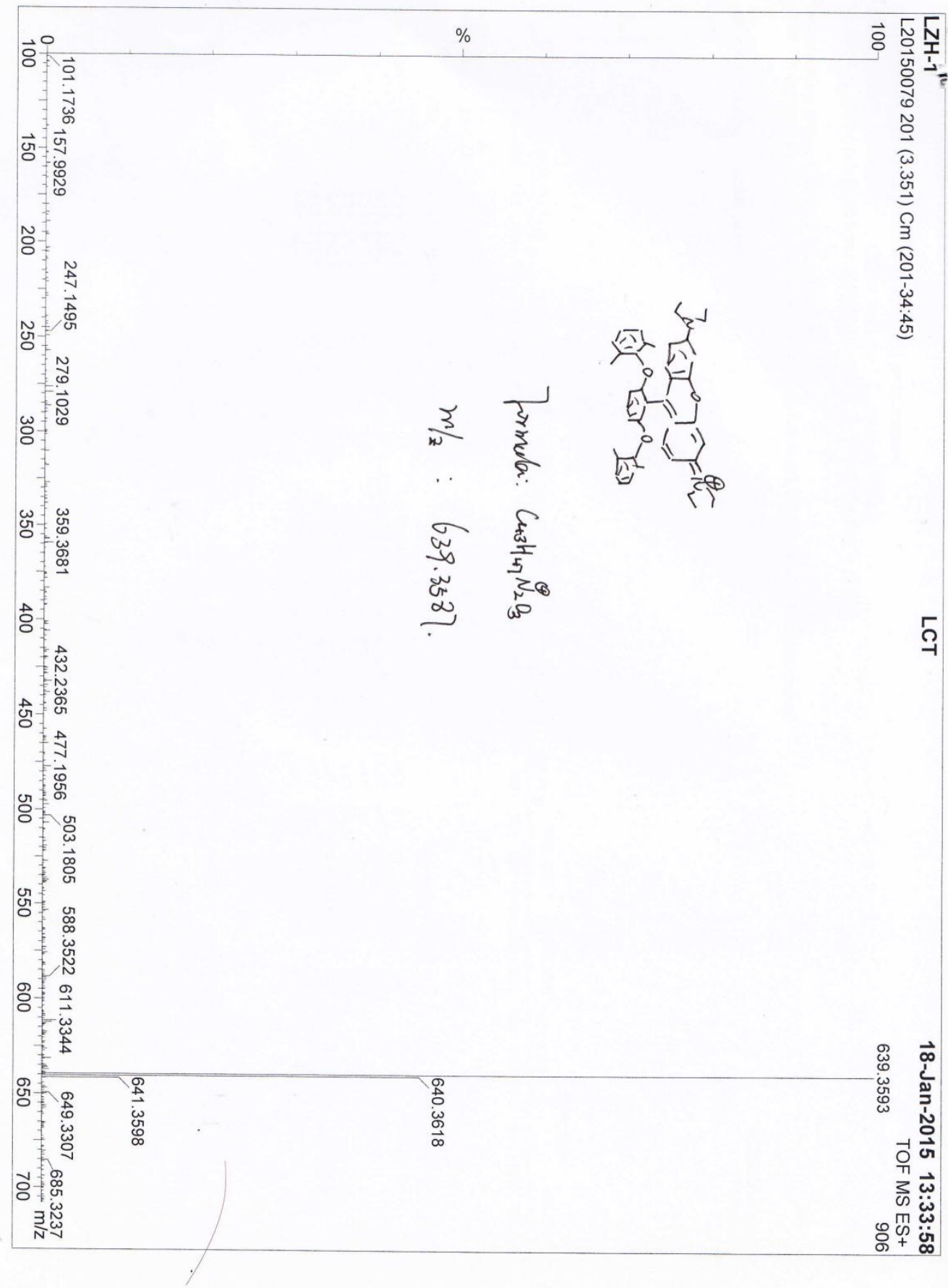

Figure S33: The HR-MS of compound 7 h. 


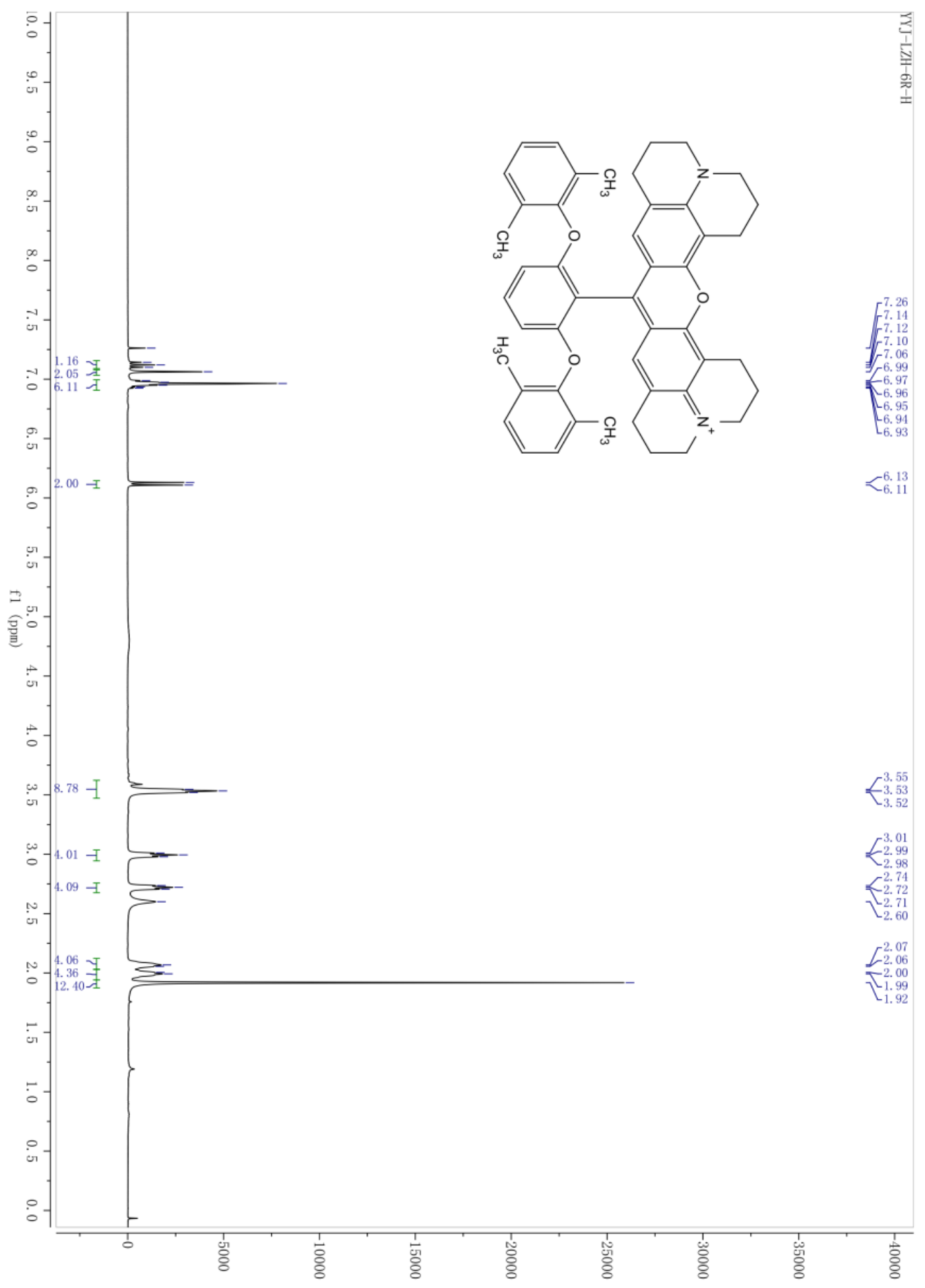

Figure S34: The ${ }^{1} \mathrm{H}-\mathrm{NMR}$ of compound $7 \mathrm{i}$ in $\mathrm{CDCl}_{3}$. 


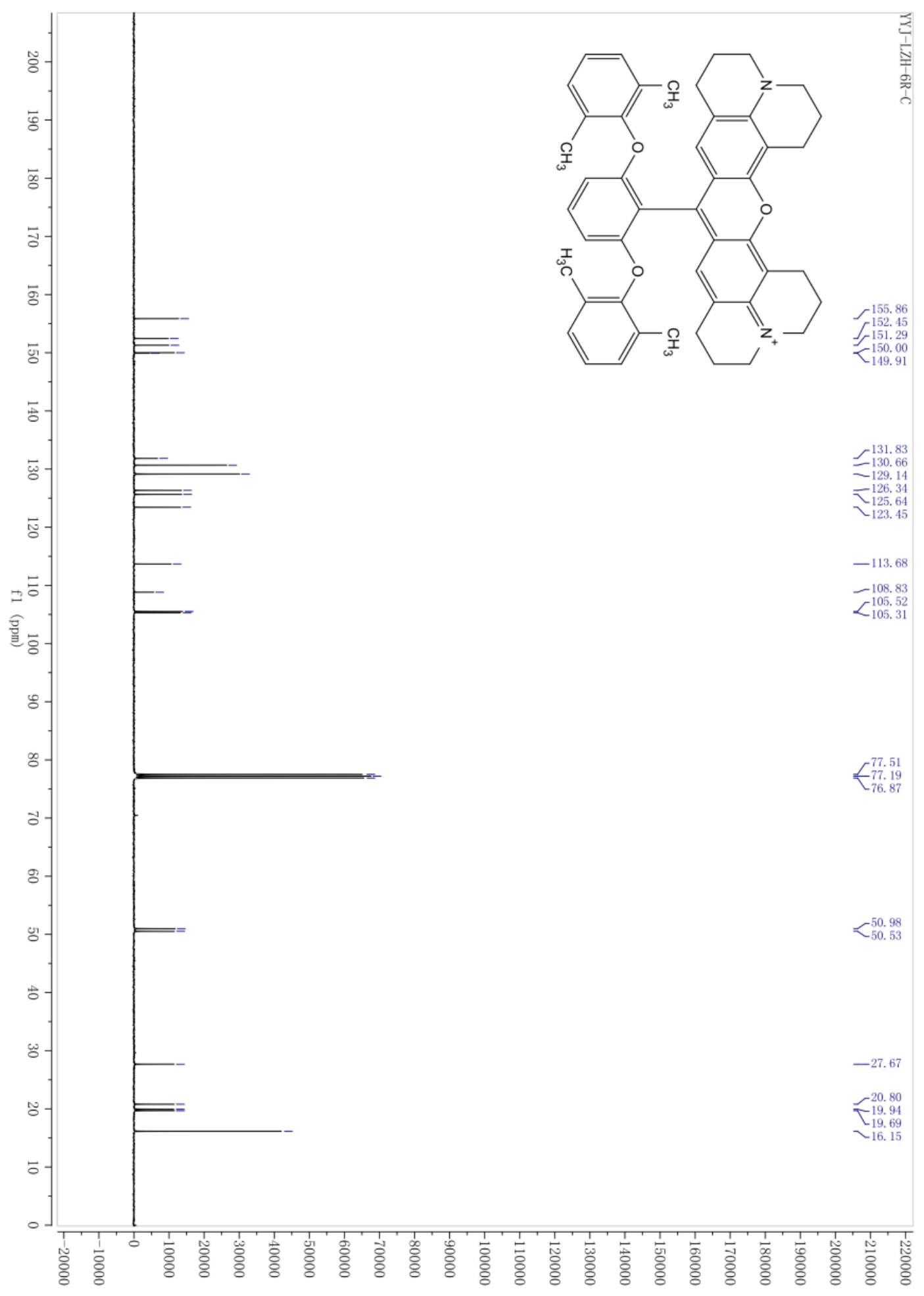

Figure S35: The ${ }^{13} \mathrm{C}-\mathrm{NMR}$ of compound $\mathbf{7 i}$ in $\mathrm{CDCl}_{3}$. 


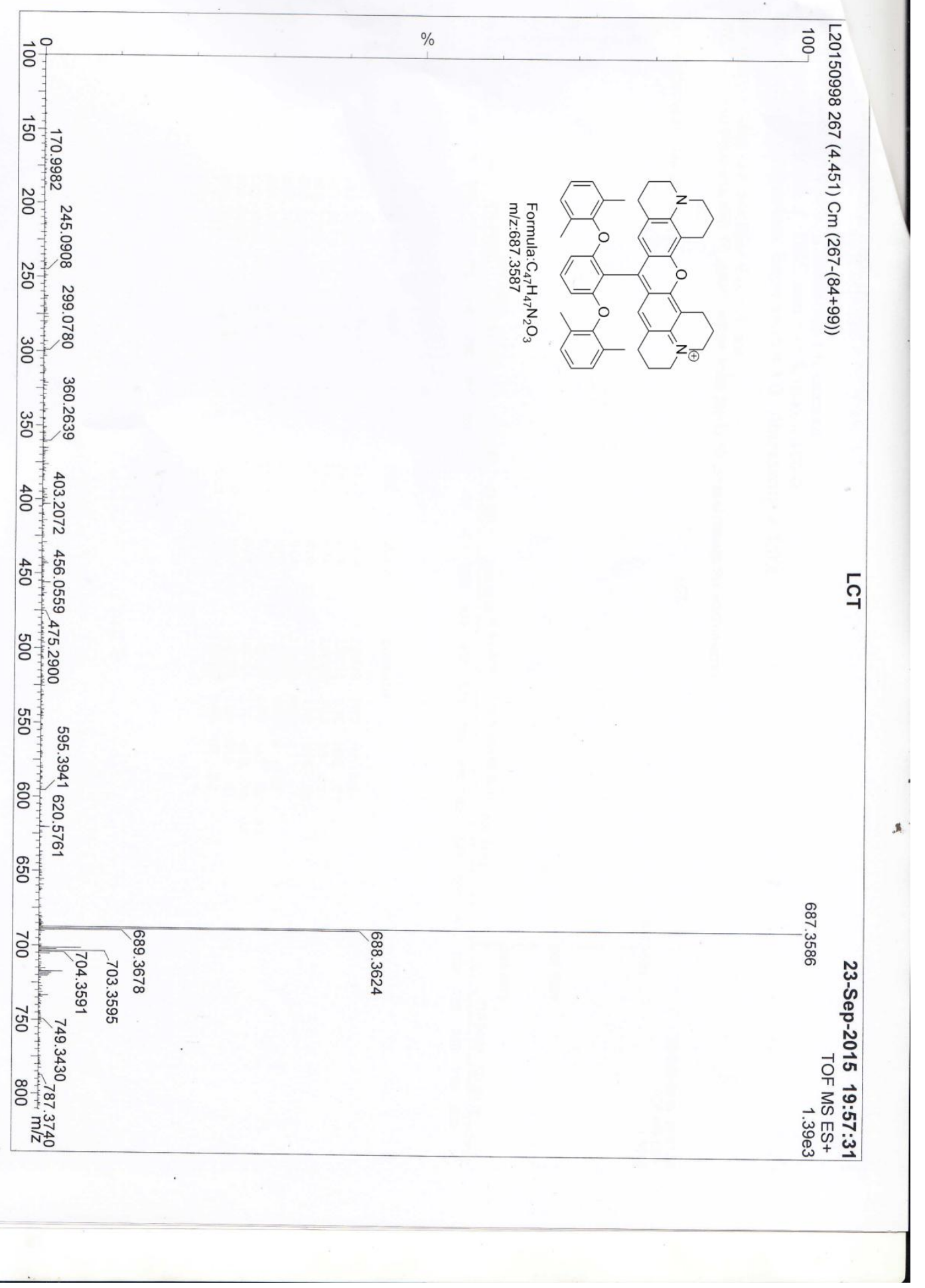

Figure S36: The HR-MS of compound 7i. 


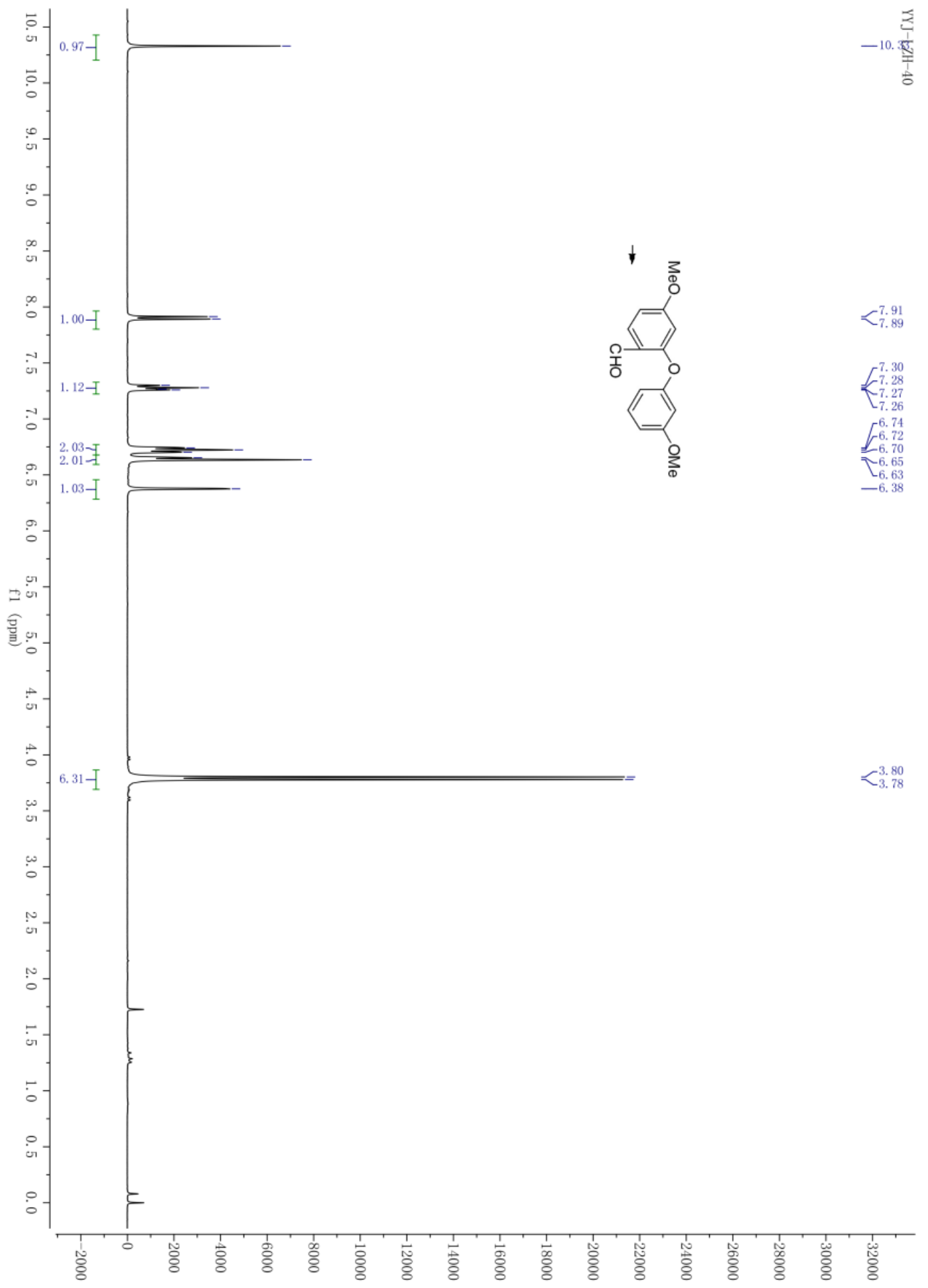

Figure S37: The ${ }^{1} \mathrm{H}-\mathrm{NMR}$ of compound $\mathbf{1 0}$ in $\mathrm{CDCl}_{3}$. 


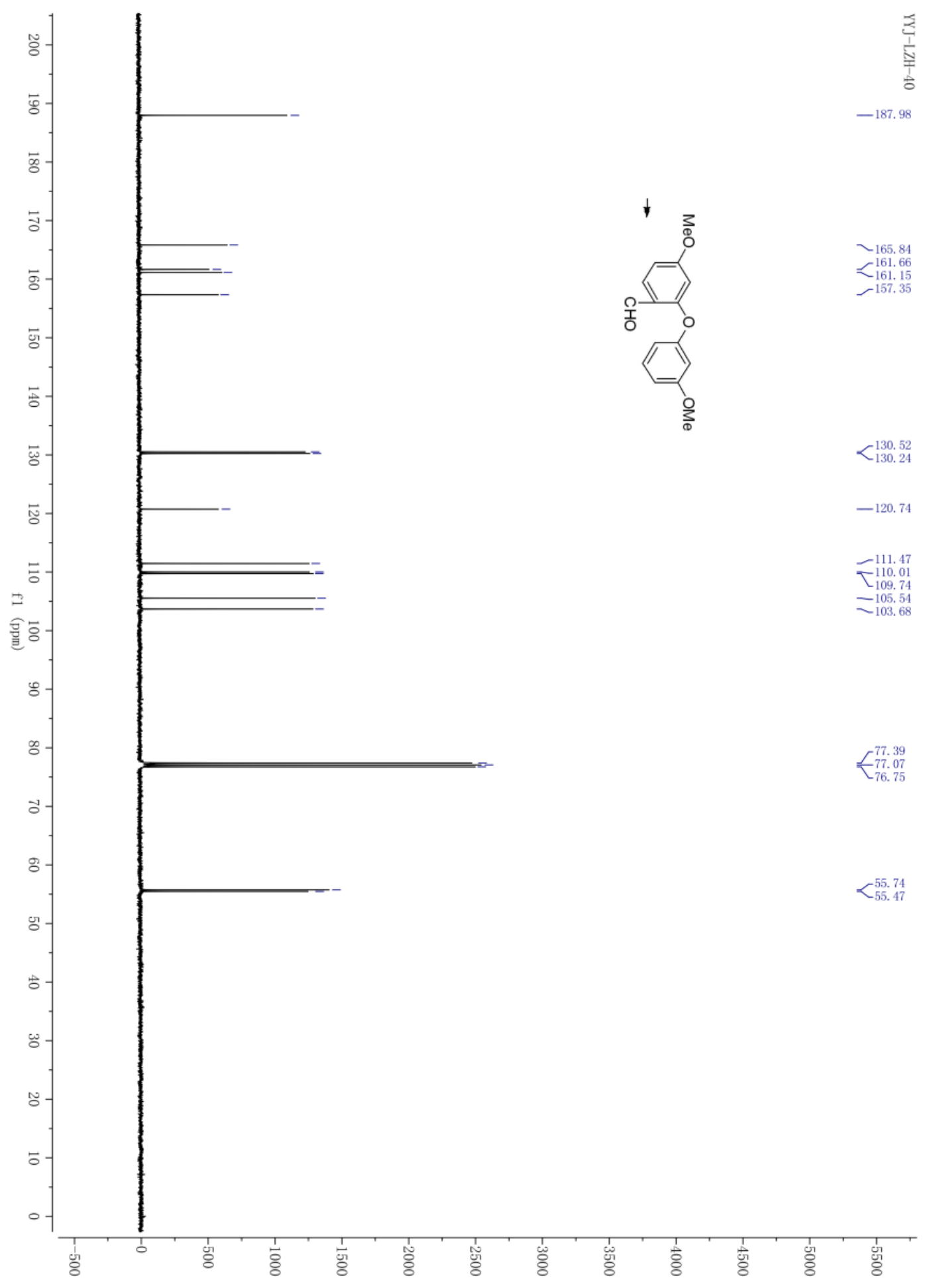

Figure S38: The ${ }^{13} \mathrm{C}-\mathrm{NMR}$ of compound $\mathbf{1 0}$ in $\mathrm{CDCl}_{3}$. 


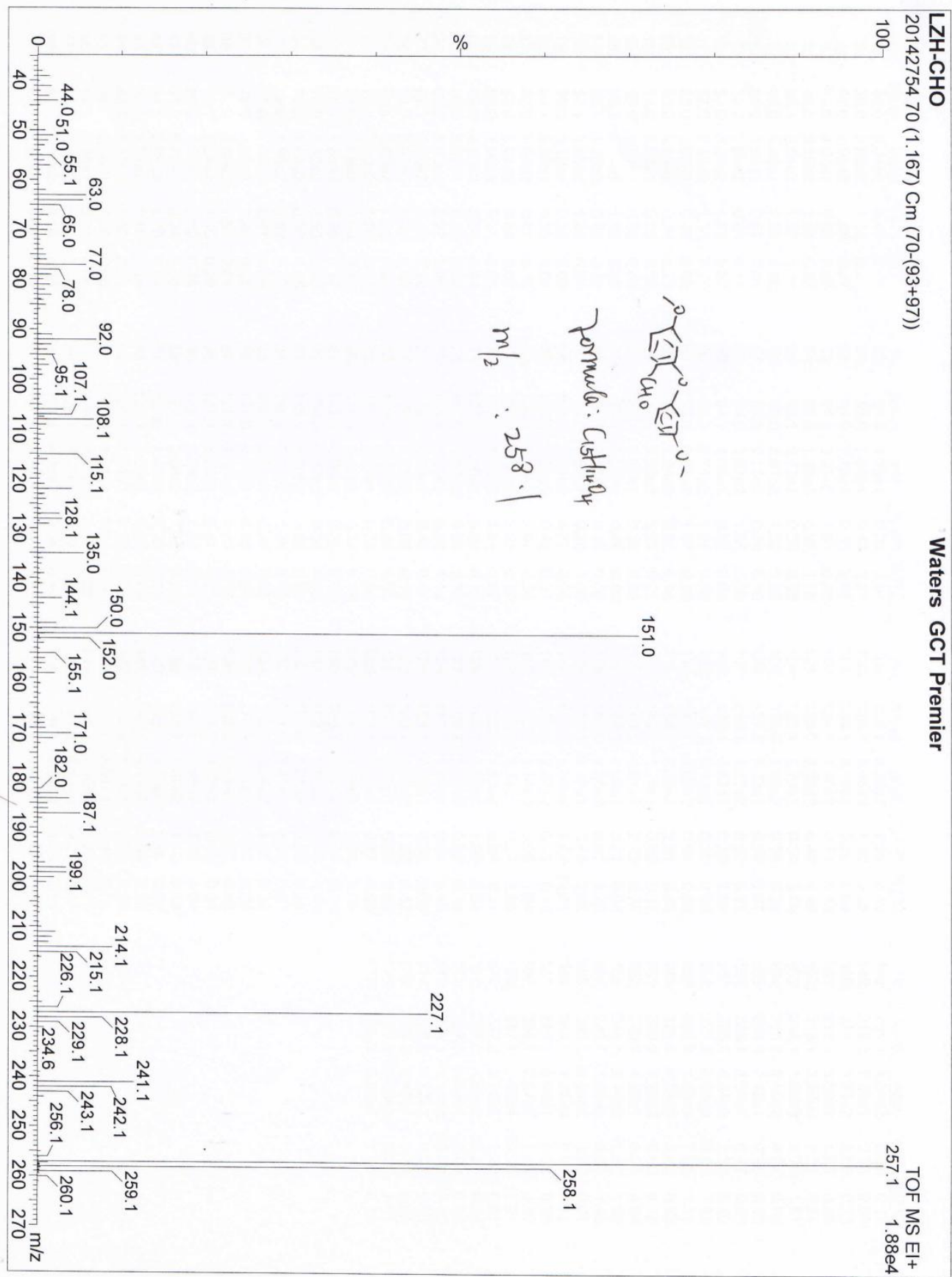

Figure S39: The HR-MS of compound 10. 


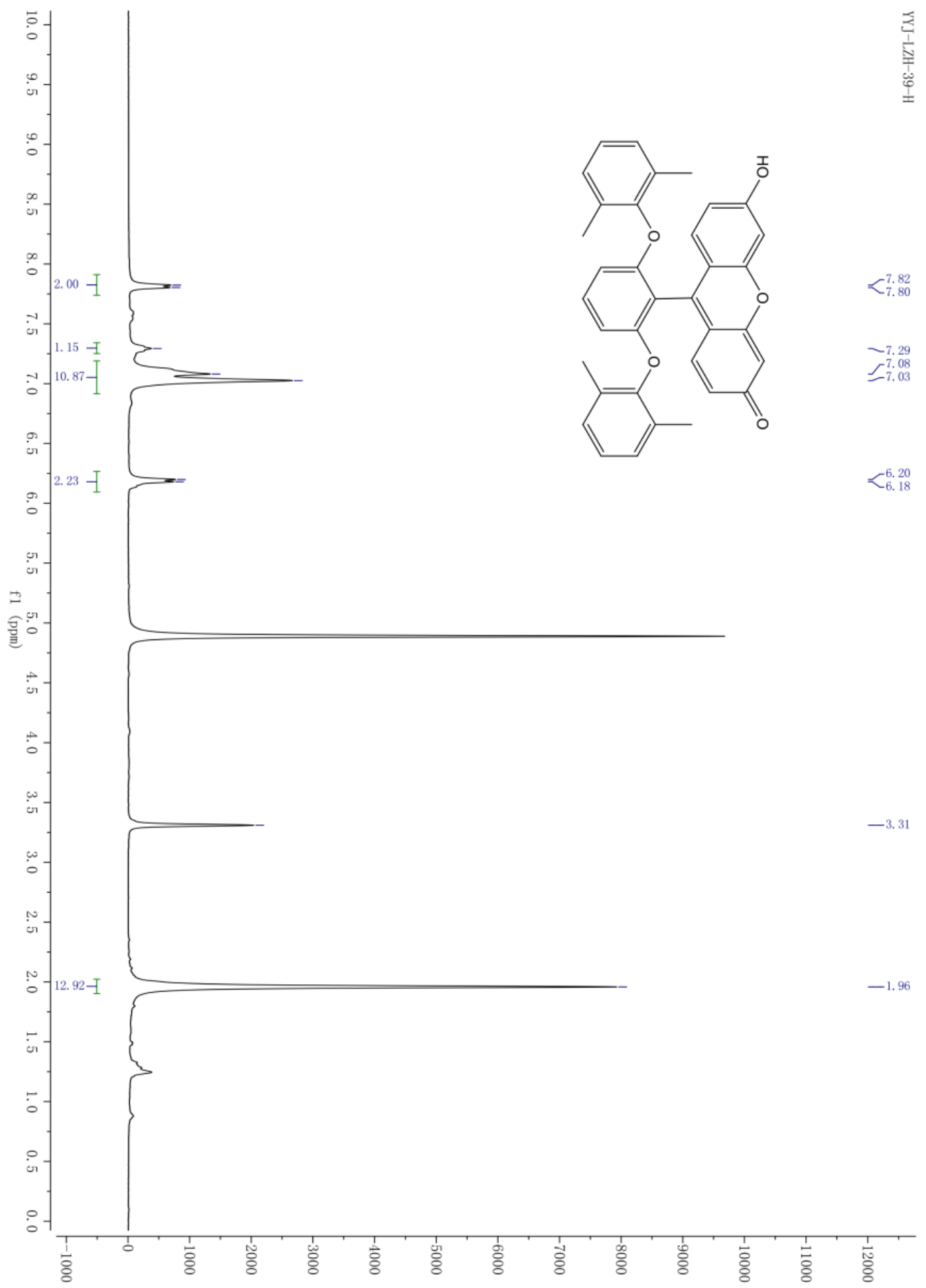

Figure S40: The ${ }^{1} \mathrm{H}-\mathrm{NMR}$ of compound $\mathbf{1 1}$ in $\mathrm{CD}_{3} \mathrm{OD}$. 


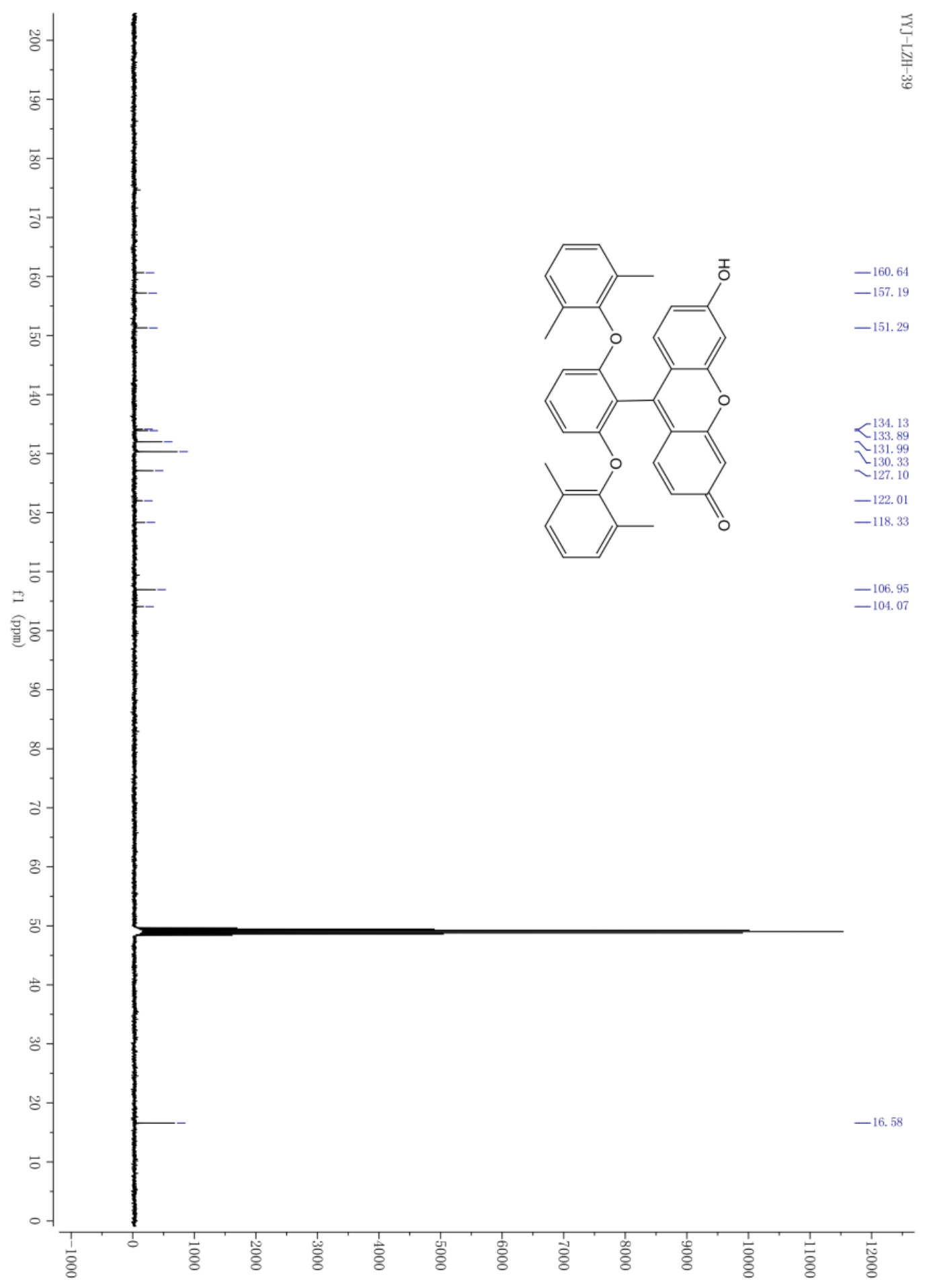

Figure S41: The ${ }^{13} \mathrm{C}-\mathrm{NMR}$ of compound $\mathbf{1 1}$ in $\mathrm{CD}_{3} \mathrm{OD}$. 


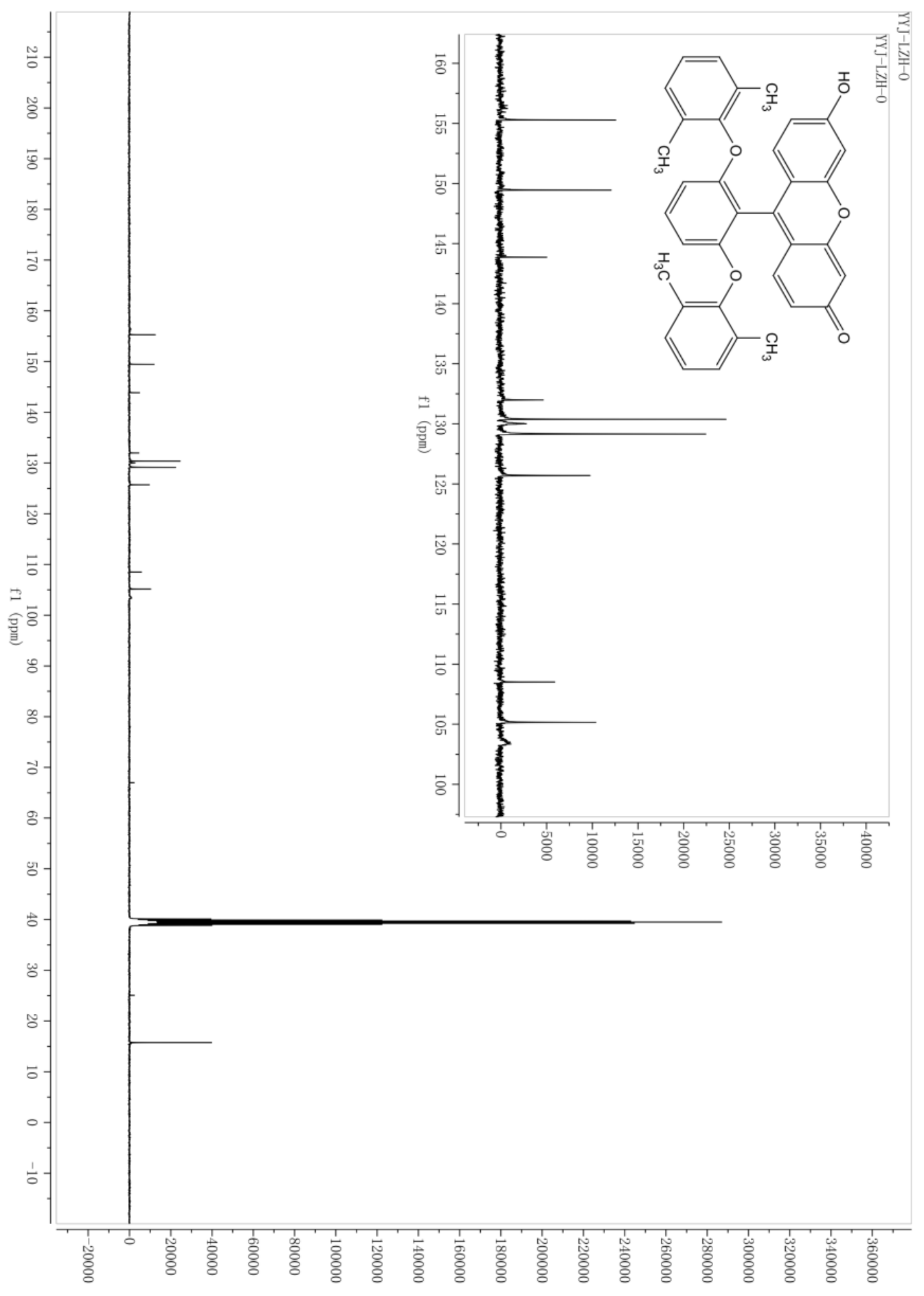

Figure S42: The ${ }^{13} \mathrm{C}$-NMR of compound 11 in DMSO- $\mathrm{d}_{6}$. 


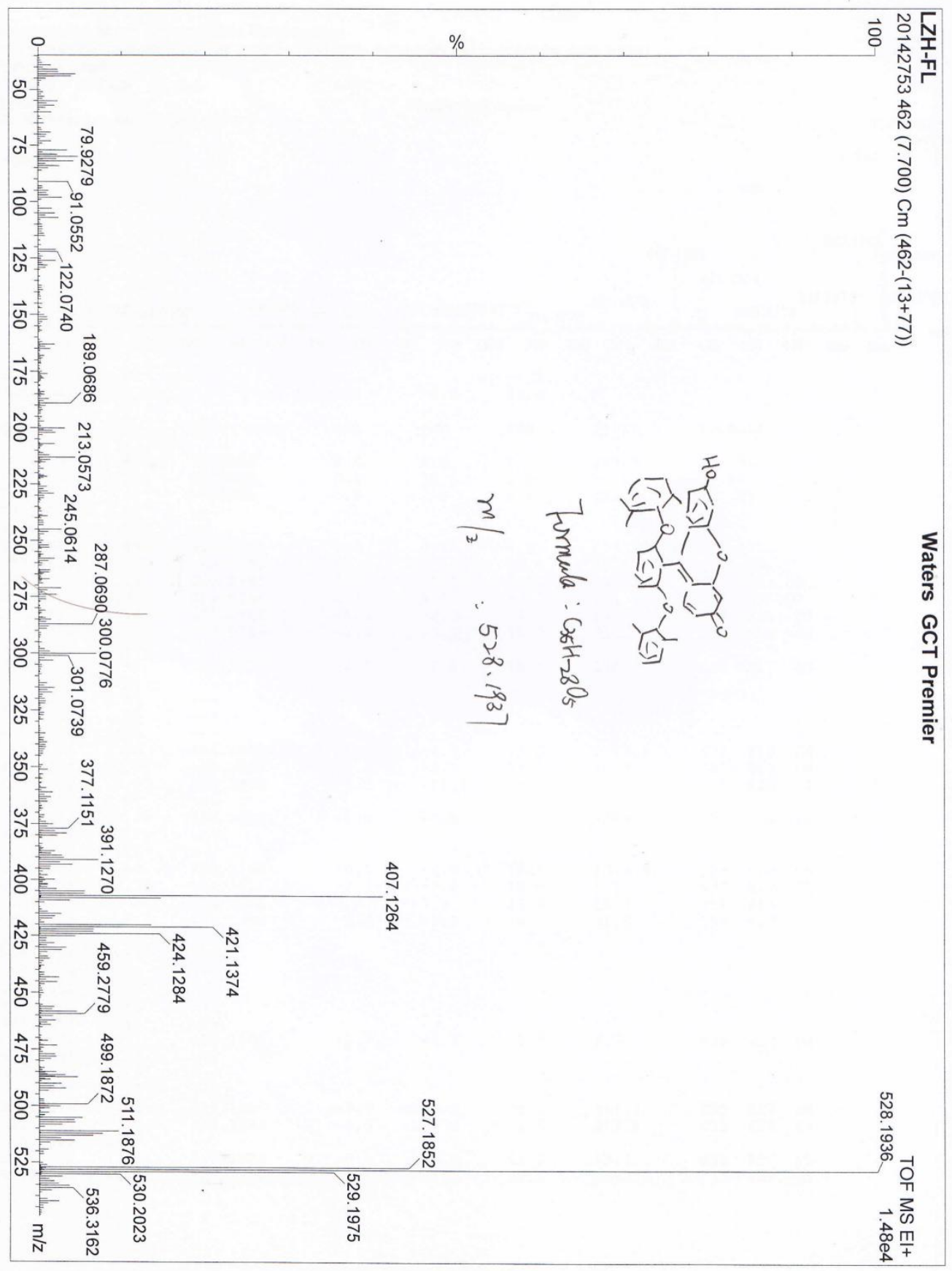

Figure S43: The HR-MS of compound 11. 


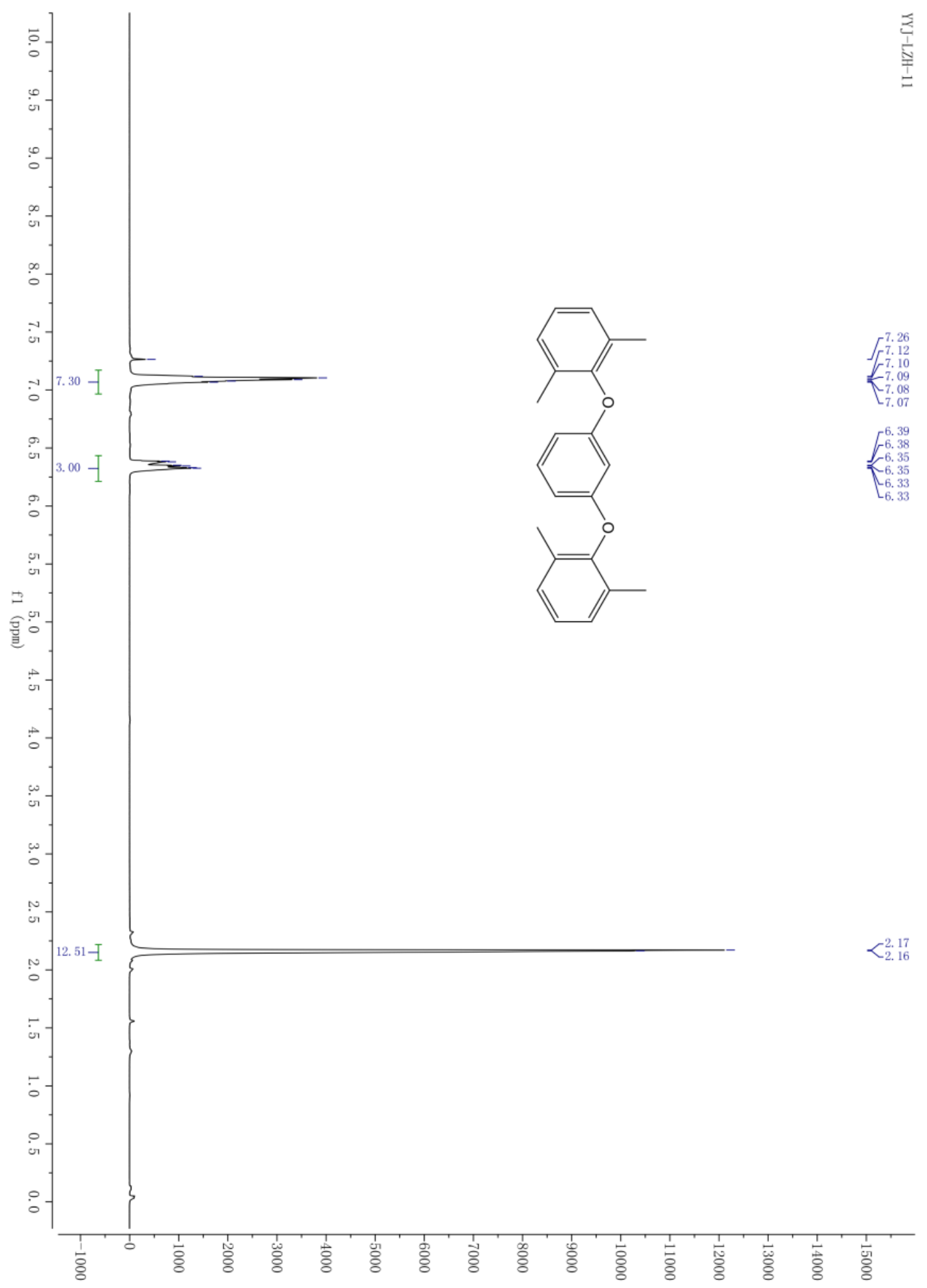

Figure S44: The ${ }^{1} \mathrm{H}-\mathrm{NMR}$ of compound $\mathbf{1 2}$ in $\mathrm{CDCl}_{3}$. 


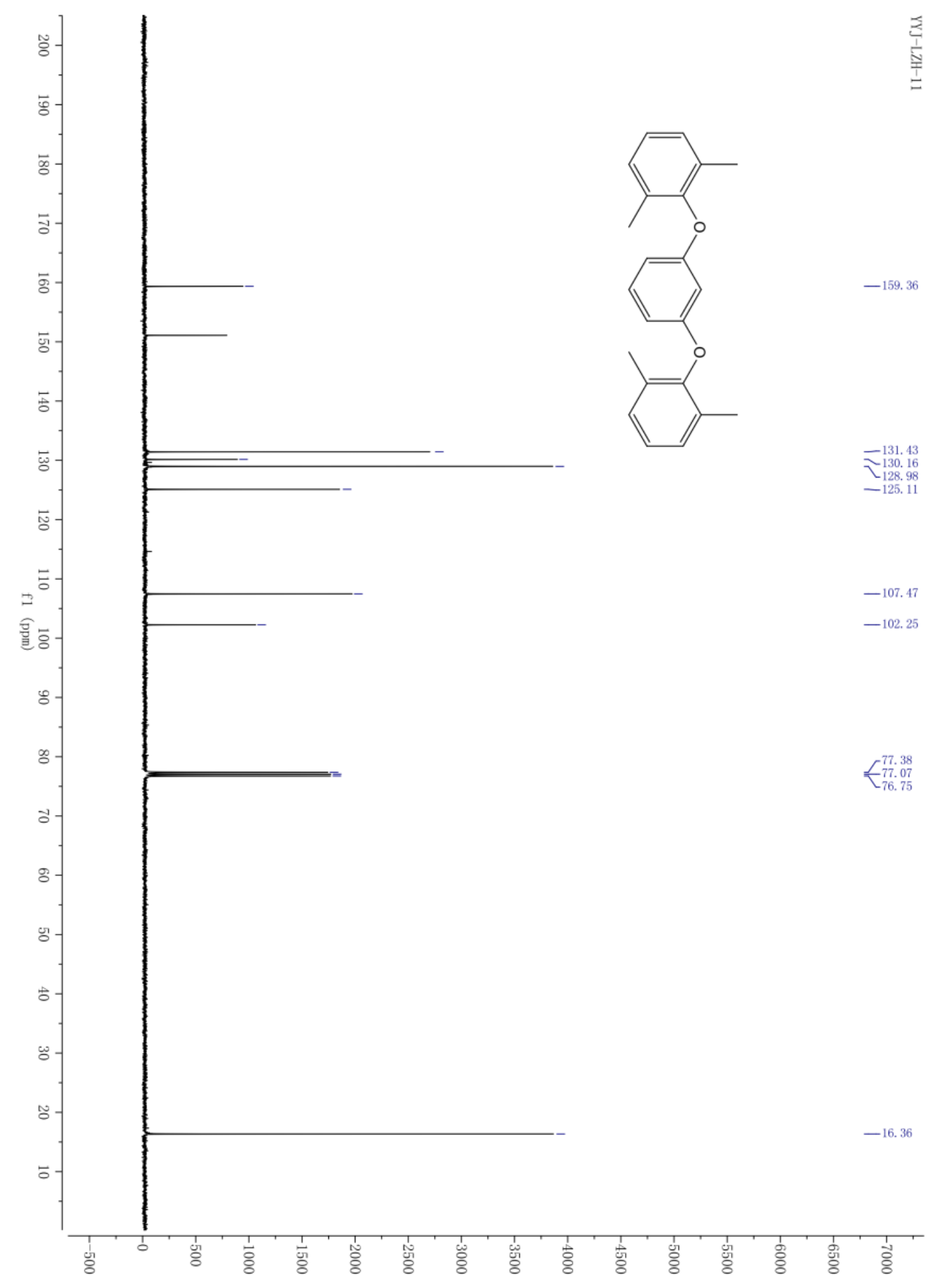

Figure S45: The ${ }^{13} \mathrm{C}-\mathrm{NMR}$ of compound 12 in $\mathrm{CDCl}_{3}$. 


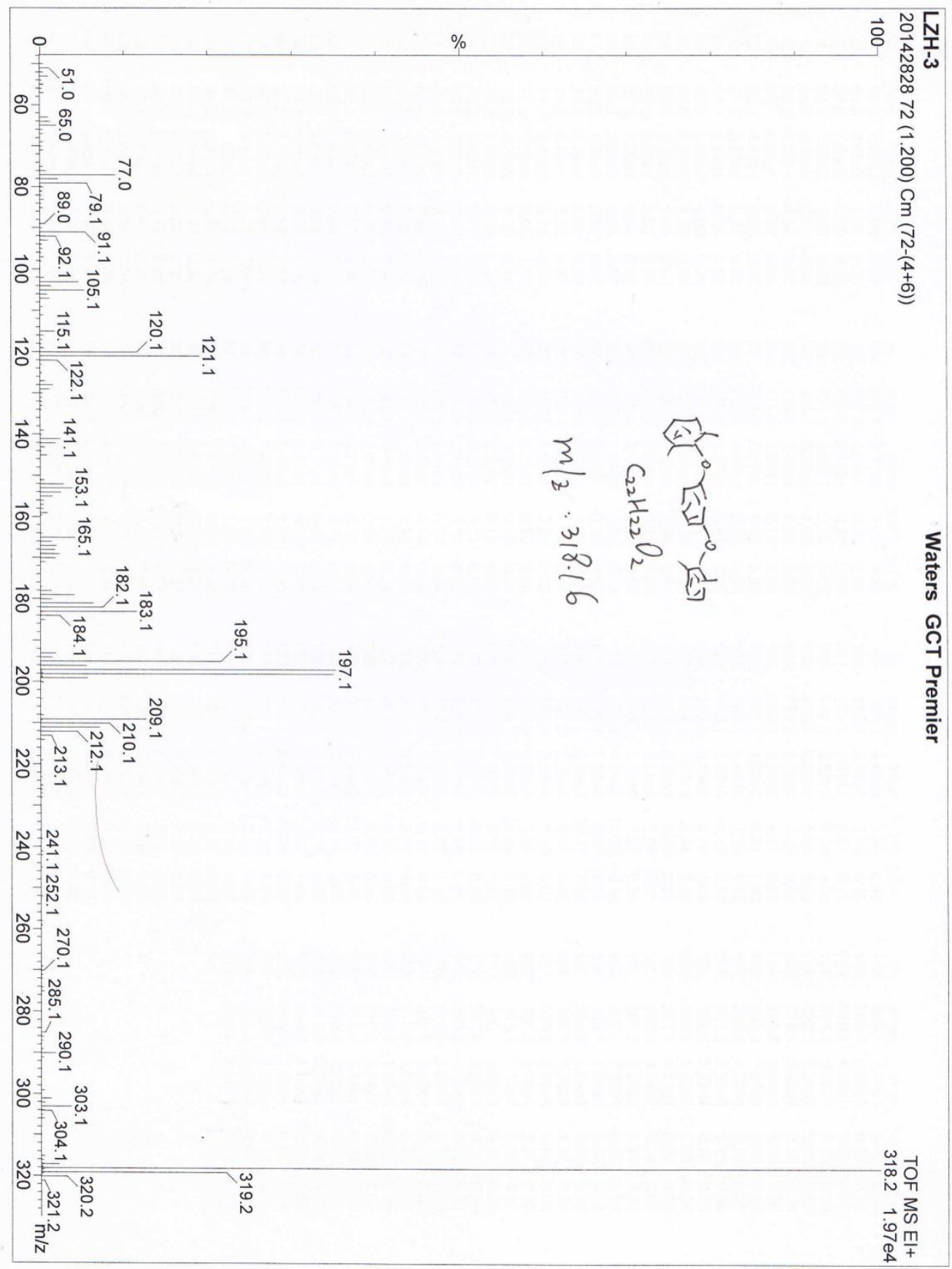

Figure S46: The EI-MS of compound 12. 